\title{
SOME EXPERIMENTAL STUDIES OF THE VIBRATIONS OF QUARTZ PLATES
}

\author{
By R. B. Wright and D. M. Stuart
}

\section{ABSTRACT}

Numerous modes of vibration of 0 and 30 degree cut circular and rectangular crystalline quartz plates were studied experimentally. Various methods were employed in studying these modes which are piezo-electrically excited. The behavior of lycopodium powder applied to the vibrating faces proved to be the most fruitful source of information. A number of photographs of the patterns thus formed are produced and described. Although of limited utility two mechanical devices also were employed in these studies.

The direction of maximum radial displacement was determined for the two active lower frequency modes of $0^{\circ}$ circular plates. It was found that these directions are nearly parallel to directions of critical values of Young's modulus. Facts were disclosed concerning. specially oriented rectangular plates and rods. Experimental values of Young's modulus based on vibration frequencies of the latter were found to agree closely with corresponding values computed from a known theoretically derived expression. Rough experimental verification of the direction of one of the critical values of Young's modulus was obtained.

Equations are derived for the modulus of rigidity and Poisson's ratio for crystalline quartz as functions of orientation, and graphs of these two functions as well as of Young's modulus are given.

Methods are indicated, which may prove advantageous, of rigidly mounting quartz plates.

\section{CONTENTS}

I. Introduction

II. Experiments of a general nature

2. Studies of powder patterns formed on the surface of plates-- 523

(a) Zero-degree circular plates_._. 524

(b) Zero-degree square plates_._. 527

(c) Thirty-degree circular plates

(d) Thirty-degree square plates_._. 529

(e) Comments concerning surface power patterns_._-_- 530

3. Studies of powder patterns formed by air currents emanating

from the periphery of plates

(a) Zero-degree circular plates._._. 530

(b) Zero-degree square plates_._. 531

(c) Thirty-degree circular plates_... 531

(d) Thirty-degree square plates____._. 531

(e) Specially oriented 0 and 30 degree cut rectangular

(f) Comments concerning air current patterns

III. Experiments of a more specific nature
1. Study of the air currents emanating from the periphery of circular $0^{\circ}$ plates.....

2. Studies of the displacement of the periphery of circular plates by means of a probing mechanism

(a) First mode of a $0^{\circ}$ circular plate

(b) Second mode of a $0^{\circ}$ circular plate

(c) The mode of a 36.03 by $4.805 \mathrm{~mm} 0^{\circ}$ circular plate responding at $136 \mathrm{kc}$

(d) Comments concerning results of probing studies..--

IV. Comment and conclusion

V. Supplementary Note. The development of Poisson's ratio and the modulus

VI. Appendix I. The development of Poisson's ratio and the modulus of rigidity for crystalline quartz

532

534

536

VII. Appendix II. The evaluation of Young's modulus 519 


\section{INTRODUCTION}

That branch of the theory of elasticity dealing with the vibrations of isotropic solid bodies may be said to be still in its infancy, even though it covers to-day quite an extensive field of endeavor. With few exceptions the theory in its present state of development allows the handling of only the simpler cases in an approximate manner. The manifest limitations appear to be principally of a mathematical nature. This situation becomes painfully evident as a definite impediment in the specialized study of piezo electrically excited oscillations of quartz plates such as are utilized in the art of radiocommunication. A second and formidable impediment is found in the fact that quartz, like other crystalline substances, is not isotropic. A third factor tending to impede progress in the study lies in the fact that owing to the necessary precision in present-day frequency requirements, inexact solutions can not be expected to yield a large degree of satisfaction. Moreover, solutions of an approximate nature, in common with any simple exact solutions that may be found by considering special cases, may be expected to give little more than a glimpse at the manifold infinity of possible modes of response.

The various experimental studies of the modes of vibration of quartz plates described in this paper were undertaken in an attempt to gain information which it was hoped would prove helpful in the theoretical study of the problem, as well as useful in practice.

\section{EXPERIMENTS OF A GENERAL NATURE}

\section{STUDIES OF GLOW-DISCHARGE PATTERNS}

The method employed in studying the piezo-electrically excited oscillations of cylinders cut from crystals of quartz, which was described in a paper by Hund and Wright, ${ }^{1}$ was tried on circular and square plates of quartz. Briefly, this method consists in the observation of the various patterns created by the resonance radiation of the gas molecules, usually termed glow discharge, accompanying the piezo-electrically excited oscillations or vibrations of the quartz bodies in an atmosphere of helium under a pressure of a few millimeters of mercury. The vacuum tube oscillator circuit used to sustain the quartz plate in vibration in this second application of the method is shown in Figure 1. As did the one previously used, it incorporates sufficient regeneration to afford independent oscillation. The quartz plate to be studied is placed on a plane metallic surface which serves as one electrode. As the upper electrode, a fine wire mesh or screen is used. This upper electrode is not distinguishable in the photographs of the phenomenon appearing at the surface of the quartz plate, because of the fineness of the wire and owing to the fact that it was supported somewhat above the face of the quartz plate on which the camera was focused.

Photographs of some of the various patterns observed are shown in Figure 2. As indicated, the quartz plates appearing in these 12 photographs are of the $0^{\circ}$ or Curie cut variety; that is, were so oriented in the process of cutting that the faces of the plate lie perpendicular 1 August Hund and R. B. Wright, New Piezo Oscillations With Quartz Cylinders Cut Along the Optical
Axis. B. S. Jour. Research, 4, pp. 383-394, 1930; or Proc. I.R.E., 18, pp. 741-761; 1930, 
to an electric axis. In the case of the square plates, a major face (one of the faces largest in area) was in turn so oriented in its plane that two of its edges lie perpendicular to the optic axis, requiring, of course, that the remaining two edges of this face lie perpendicular to the mechanixal axis. (A more detailed treatment of the subject of orientation is involved in the accompanying appendixes).

It is common knowledge that the frequencies at which a given quartz plate will vibrate with appreciable amplitude in a vacuum tube circuit incorporating external regeneration are very numerous indeed. In 1923 Pierce $^{2}$ published a so-called spectrum of response frequencies. He pointed out that at the majority of these numerous modes the plate responded with small amplitude, and that of the few at which the plate responded with relatively large amplitude in a regenerative circuit of this nature, one could be identified with each of the very limited number which he found would respond in his single tube piezo oscillator. He distinguished between the action of the

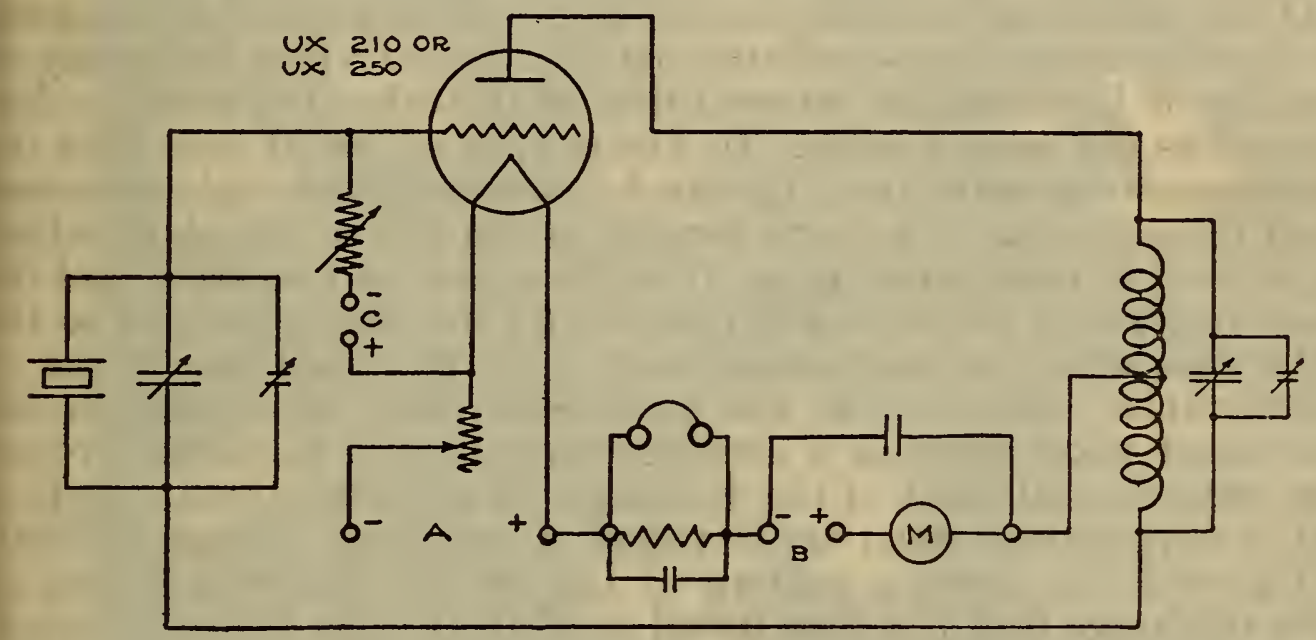

FIGURE 1.-Type of vacuum tube circuit used in the various experimental studies

two types of circuits on a quartz plate by describing the effect of the former type as resonating and that of the latter as oscillating. This is a good distinction to be made when possible. However, in many cases no sharp distinction can be drawn. This is particularly true in the case of the highly regenerative circuit (fig.1), used in the studies to be described here. A large number of the modes studied could be sustained indefinitely, although unstably so, in this circuit.

It has been known for some time that a $0^{\circ}$ circular quartz plate may be caused to execute sustained free vibrations at three different frequencies ${ }^{3}$ when placed in that type of piezo-oscillator circuit in common use, in which the piezo-electric element is connected either between the grid and the filament, or the grid and plate of a vacuum tube, and in which a condenser in parallel with an inductor is employed in the anode branch. ${ }^{4}$ The ratio of the two lower of these frequencies of response is roughly $1 / \sqrt{2}$. Furthermore, it has been recognized

2 G. W. Pierce, Piezoelectric Crystal Resonators and Crystal Oscillators Applied to the Precision Calibration of Wave Meters. Proc. A. A. A. S., 59, pp. 81-106; 1923.

3 A. Hund, Uses and Possibilities of Piezo-Electric Oscillators, Proc. I. R. E., 14, pp. 447-469; 1926.

1 The particular type referred to here is described more fully in the paper by $A$. Hund referred to in footnote 3 . 
for a number of years that the direction (in a plane parallel to a face, and with respect to some crystallographic axis, for example, the principal or optic axis) in which the maximum radial displacement takes place differs for the two lower of these three modes of response of circular plates. $^{5}$ In Figure $2, A$, is shown the phenomenon that appears when a $0^{\circ}$ circular plate is caused to oscillate in the described regenerative circuit and electrode system, at that one of these three modes which responds at the lowest frequency. This mode, for the sake of brevity, shall be designated as the first mode.

The phenomenon appearing agrees in pattern or configuration with observations made by Namba and Matsumura, ${ }^{6}$ and also by Meissner. ${ }^{7}$ No favored direction of displacement is indicated, unfortunately. The phenomenon appears as a concentric circular discharge of rough definition. (The periphery of the lower electrode which, because of its smaller size, may be indistinctly seen through the quartz plate, should not be confused with the circular discharge pattern which occupies less than half the area of the face of the quartz plate.)

Of the three modes of vibration of a $0^{\circ}$ circular plate which respond in the customary piezo-oscillator circuit, the one whose frequency of response is intermediate between that of the other two shall be designated as the second mode. In Figure $2, B$, we see at once that the phenomenon accompanying this mode varies with the angle measured from the optic axis in a plane parallel to the face of the plate, which angle shall be designated by $\gamma$. It might appear at first hand that the maximum radial displacement must take place nearly parallel to the optic axis, which is represented roughly by the white line in the 12 photographs. However, as was determined later, the maximum displacement takes place in a direction normal to a diameter through the maximum intensity of the discharge. The region about a node of radial displacement must be the region of maximum voltage gradient.

Figure $2, C$, shows a pattern of this gas resonance radiation or glow discharge that has been found in all $0^{\circ}$ circular plates observed. The frequency at which this pattern appears for the particular plate, is $241 \mathrm{kc}$. In Figure $2, D, E$, and $G$ are shown patterns which are of frequent occurrence. A peculiarity of these patterns is that it is difficult to cause two or more of these curious figures to appear simultaneously on the face of a plate, even though a complete pattern may consist of several. The explanation of this is not evident. The pattern shown in Figure 2, $F$, appears consistently, and is to be found on plates of various sizes. It emphasizes the difficulty of interpreting these phenomena.

The third and highest in frequency of the three modes of $0^{\circ}$ circular plate which respond in the customary piezo-oscillator circuit will be termed for brevity the third mode. This mode is often called the thickness mode. The pattern accompanying oscillation at this mode is given in Figure 2, $H$. Here is indicated the breaking up of the face of the plate into "nodes" and "antinodes." This breaking up of the face of a plate in oscillation at the third mode was roughhly indicated in Crossley's experiments on rectangular plates. ${ }^{8}$ In studies

s See A. Meissner, Untersuchungen am Quarz, Phys. ZS., 28, pp. 621-625; 1927.

- S. Namba and S. Matsumura, General Properties of Piezo-Electric Quartz and the Value of a Quartz Oscillator as a Frequency Standard, Researches of the Electrotechnical Laboratory No. 248; A pril, 1929. 7 A. Meissner, strukturbestimmung durch akustische Eigenschwingungen, ZS. f. Phys., 65, pp. 145-157; 1930.

${ }_{8}$ A. Crossley, Modes of Vibration in Piezo-Electric Crystals, Proc. I. R. E., 16, pp. 416-423; 1928. 


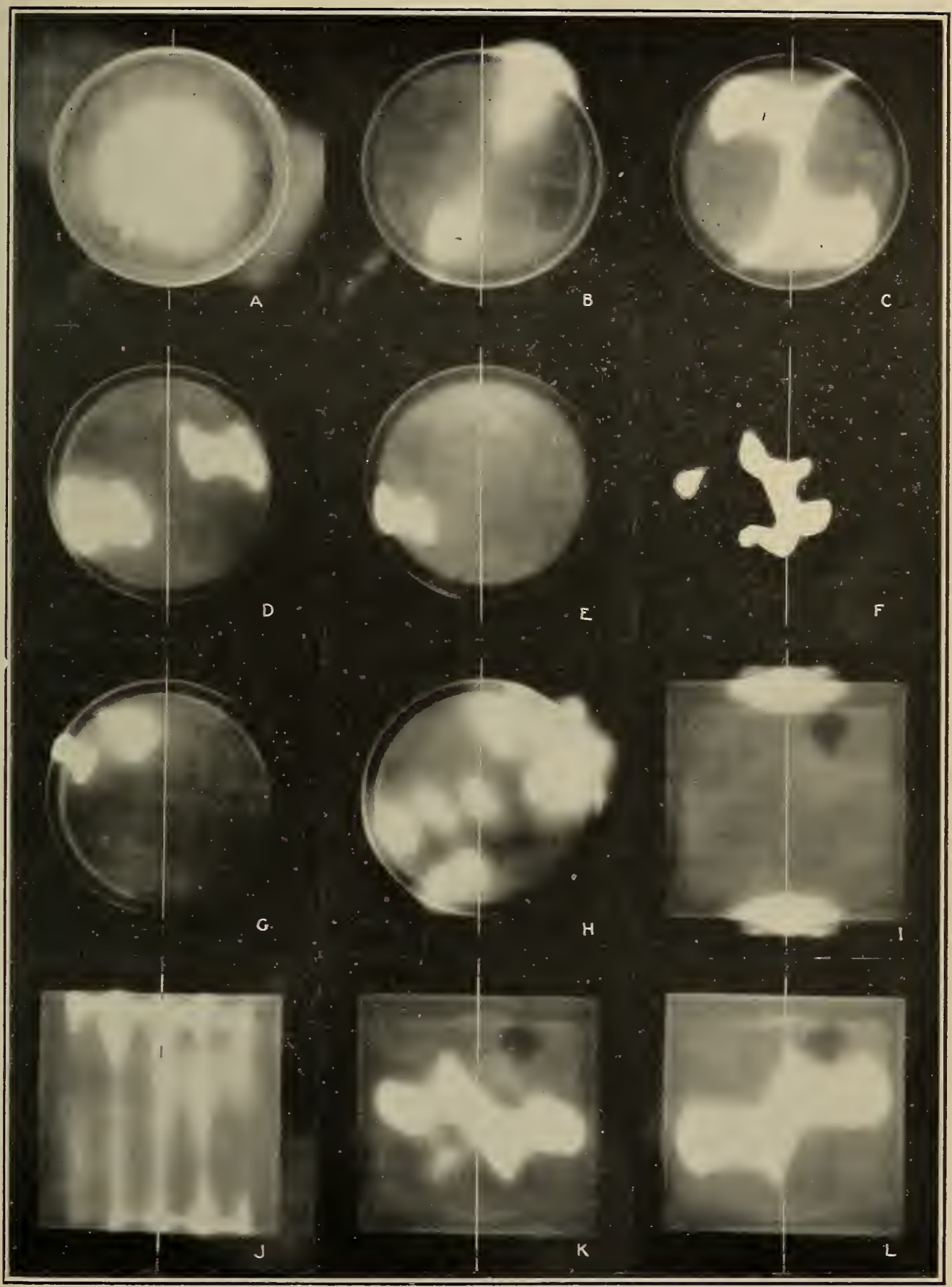

Figure 2.-Zero-degree plates

Circular plate; diameter $36.03 \mathrm{~mm}$, thickness $4.805 \mathrm{~mm}$; square plate; $\|$ optic axis $35.98 \mathrm{~mm} ; \perp$ optic axis $36.02 \mathrm{~mm}$, thickness $4.810 \mathrm{~mm}$.
$A, 75.3$ kilocycles.
$B, 106$ kilocycles.
$D, 292$ kilocycles.
$E, 397$ kilocycles.
$G, 552$ kilocycles.
$H, 599$ kilocycles.
$I, 80.4$ kilocycles.
$C, 241$ kilocycles.
$F, 431$ kilocycles.
$J, 177$ kilocycles.
$K, 210$ kilocycles.
$L, 255$ kilocycles. 
B. S. Journal of Research, RP356

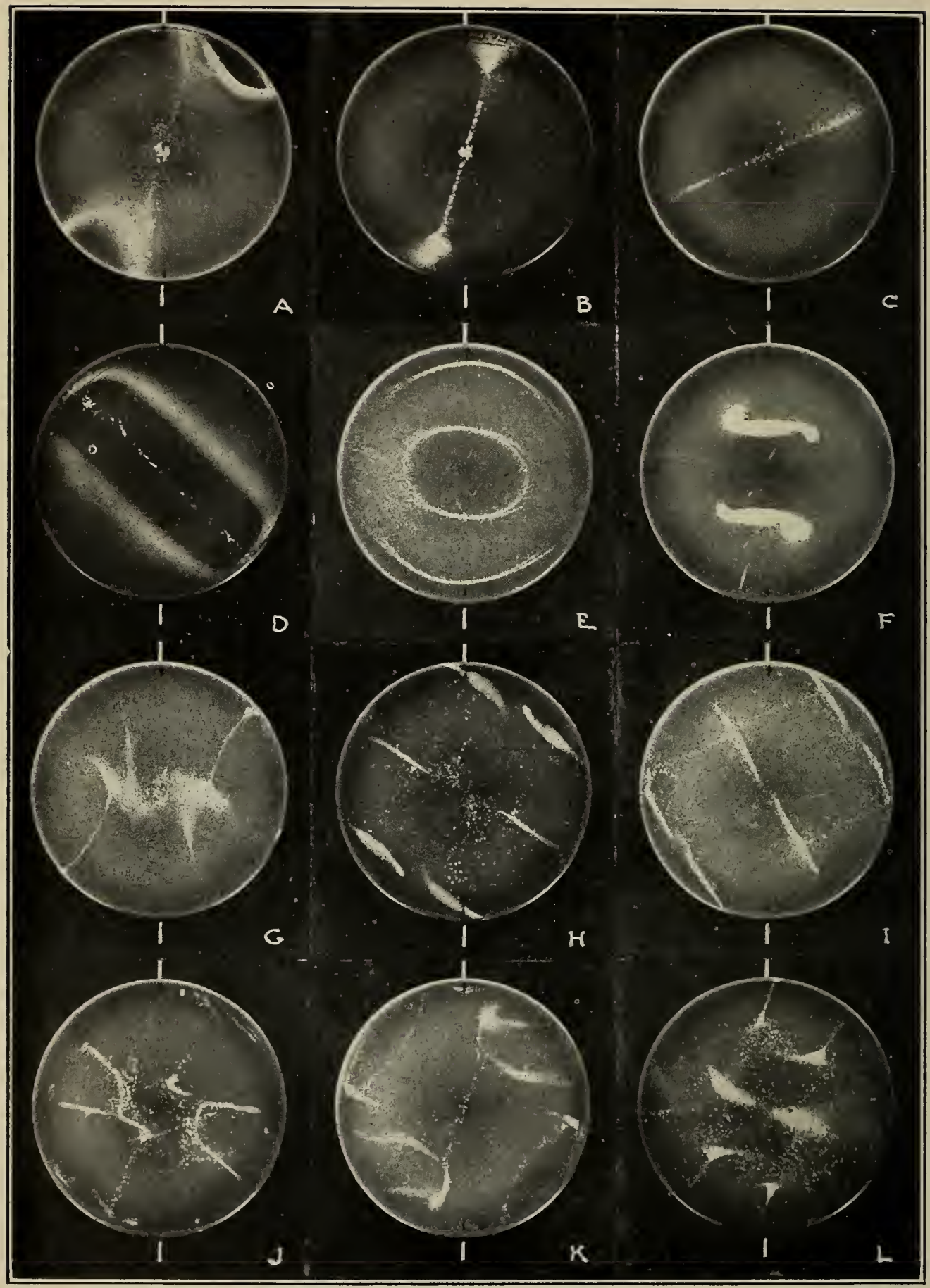

Figure 3.-Zero-degree plate

Diameter $36.03 \mathrm{~mm}$, thickness $4.805 \mathrm{~mm}$ (excepting $A$, for which dimensions are, diameter $36.16 \mathrm{~mm}$; thickness $4.815 \mathrm{~mm}$ ).

A, 74.9 kilocycles.

$R, 75.3$ kilocyeles.

$C$, 93.5 kilocycles
$D, 106$ kilocycles.

$E, 12.5$ kilocycles.

$F, 133$ kilocyeles.
$G, 146$ kilocycles.

$I I, 163$ kilocycles.

$I, 17 J$ kilocyeles.
$J, 234$ kilocycles.

$K, 236$ kilocycles.

$L, 251$ kilocycles. 
B. S. Journal of Research, RP356

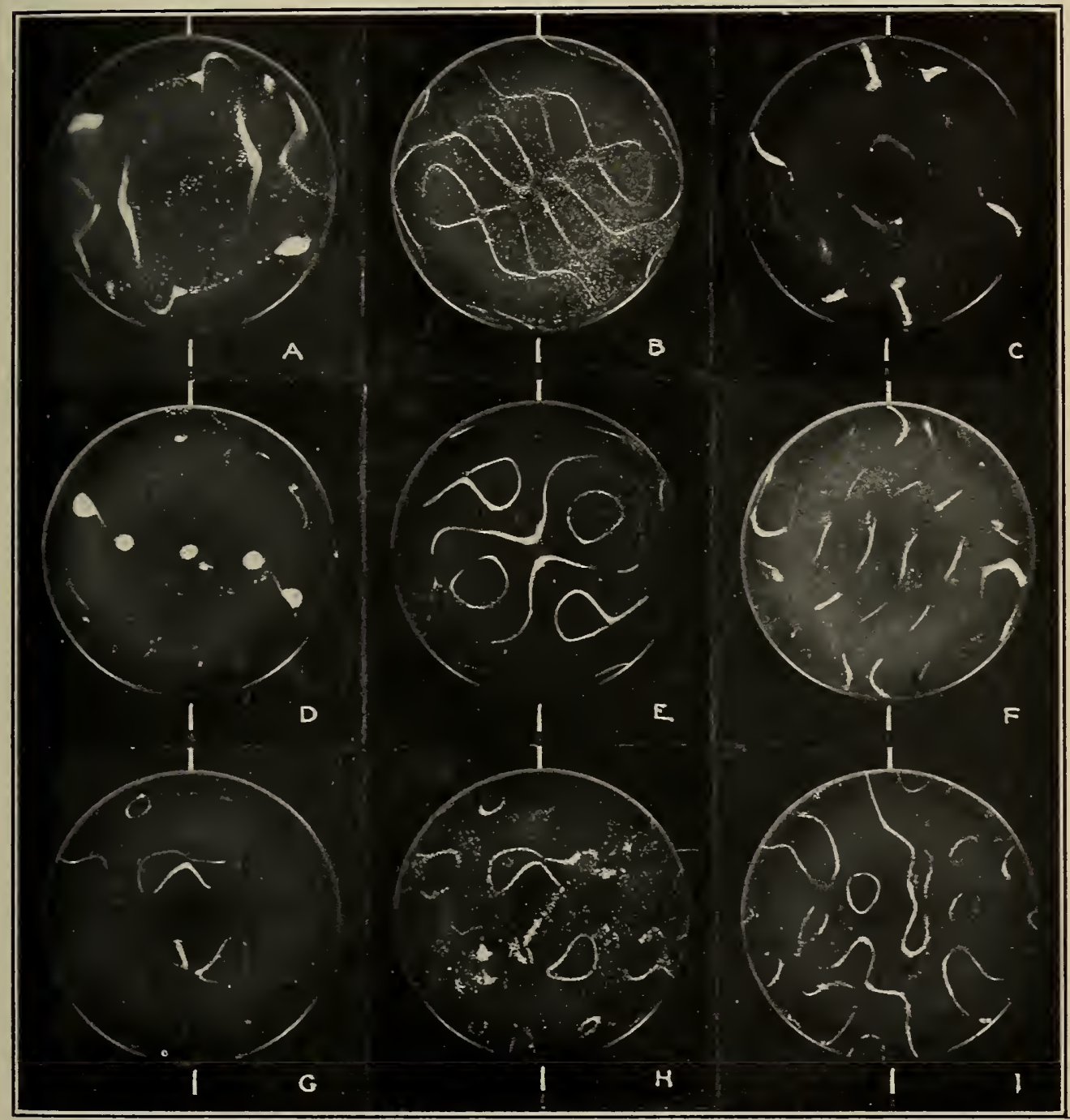

Figure 4.-Zero-degree plate

Diameter $36.03 \mathrm{~mm}$; thickness $4.805 \mathrm{~mm}$.

$A, 258$ kilocycles. $B, 360$ kilocycles. $C, 389$ kilocycles.
$D, 397$ kilocycles.

$E, 400$ kilocycles.

$F, 494$ kilocycles.
$G, 597$ kilocycles. $H, 597$ kilocycles I, 599 kilocycles. 
B. S. Journal of Research, RP356

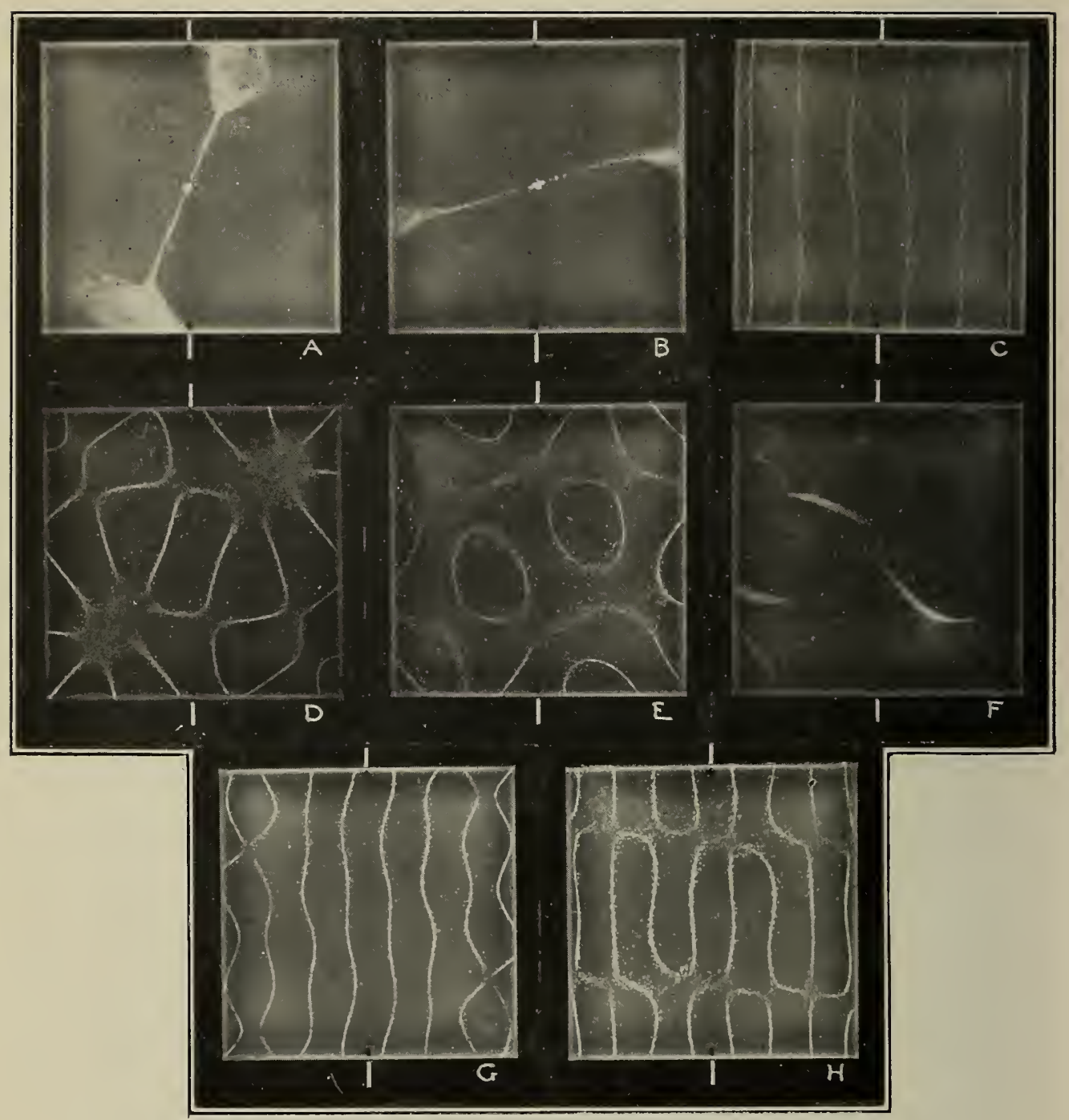

Figure 5.-Zero-degree plate

H Optic axis $35.98 \mathrm{~mm}$. $\perp$ Optic axis $36.02 \mathrm{~mm}$. Thickncss $4.810 \mathrm{~mm}$.

$A, 66.8$ kilocycles.

$B, 83.6$ kilocycles.

$C, 177$ kilocycles.
$D, 202$ kilocycles.
$E, 204$ kilocycles.

$E, 204$ kilocycles.
$F, 210$ kilocycles.
$G, 270$ kilocycles. II, 288 kilocycles. 
B. S. Journal of Research, RP356

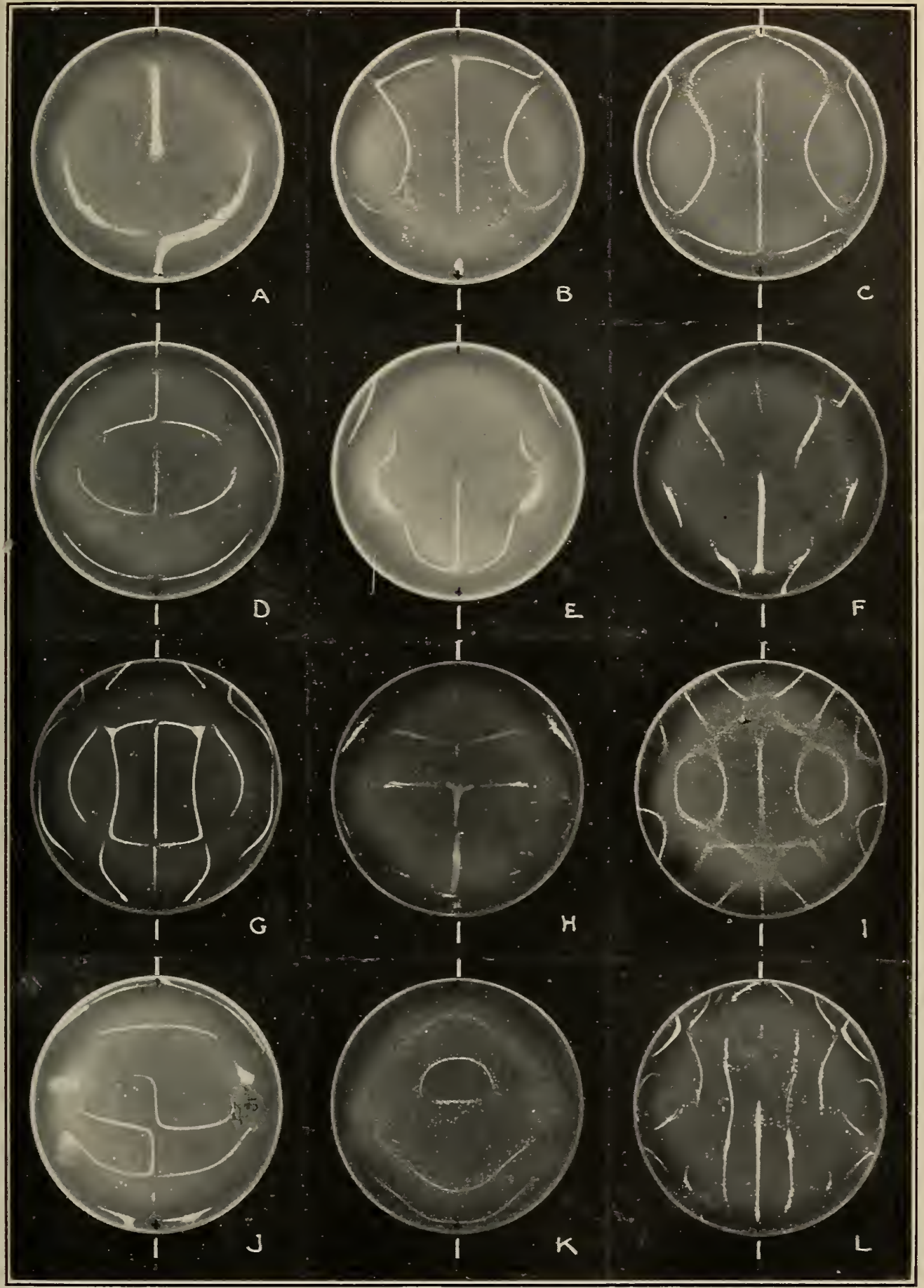

Figure 6.-Thirty-degree plate

Diameter 36.c4 mm; thickness $4.810 \mathrm{~mm}$.

$A, 91.2$ kilocycles. $B, 145$ kilocy cles. $C, 146$ kilocycles.
$D, 161$ kilocycles. $E, 181$ kilocycles. $F, 192$ kilocycles.
$G, 246$ kilocycles. $H, 250$ kilocycles. $I, 253$ kilocycles.
$J, 261$ kilocycles. $\dot{K}, 289$ kilocycles $L, 298$ kilocycles. 


\section{B. S. Journal of Research, RP356}

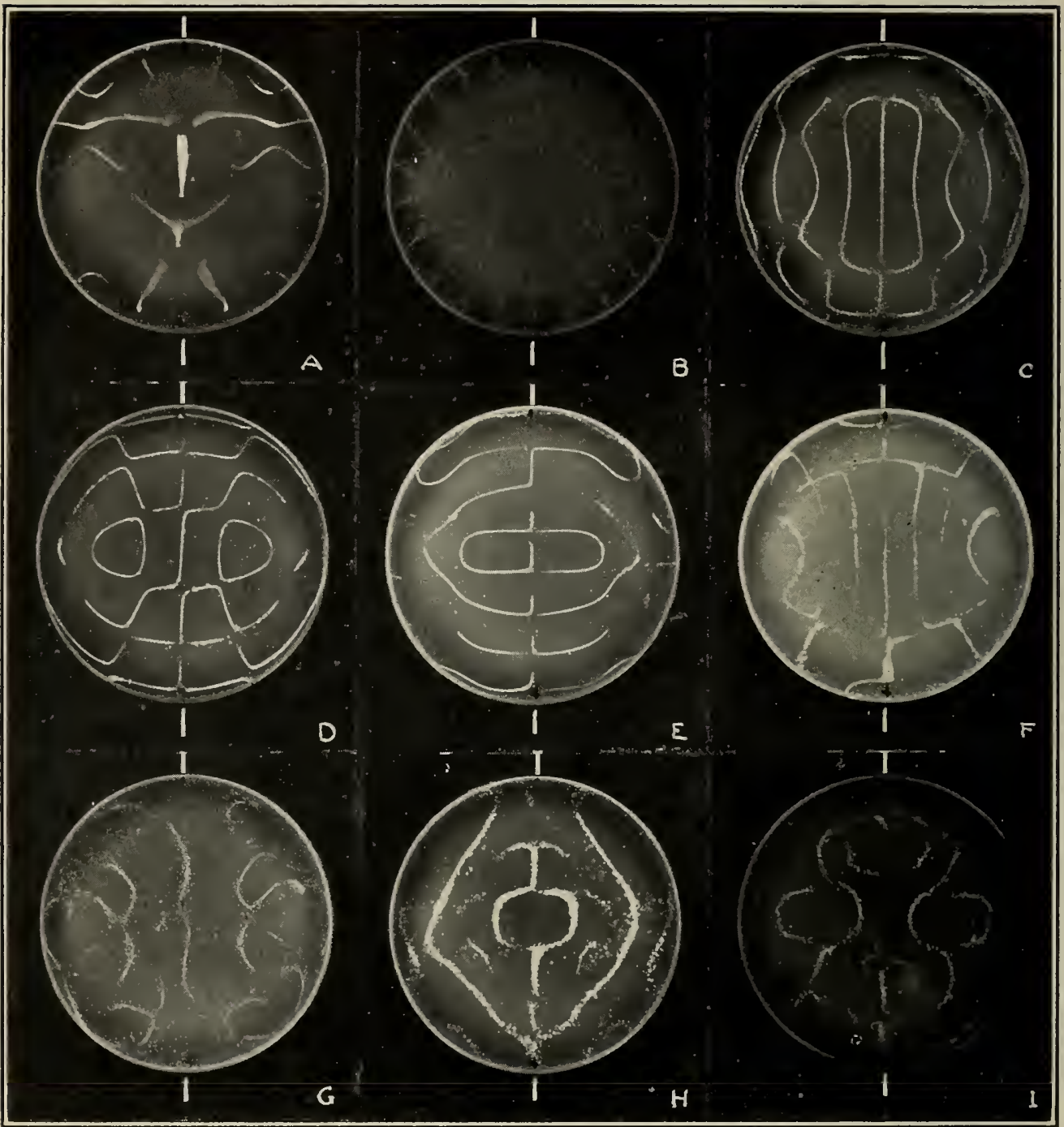

FIGURE 7.-Thirty-degree plate

Diameter $36.04 \mathrm{~mm}$; thickness $4.810 \mathrm{~mm}$.

A. 314 kilocycles.

$B, 323$ kilocycles.

C, 333 kilocycles.
$D, 346$ kilocycles.

$E, 370$ kilocycles.

$F, 402$ kilocycles.
$G, 406$ kilocycles. II, 4 C8 kilocycles. $I, 415$ kilocycles. 
B. S. Journal of Research, RP356

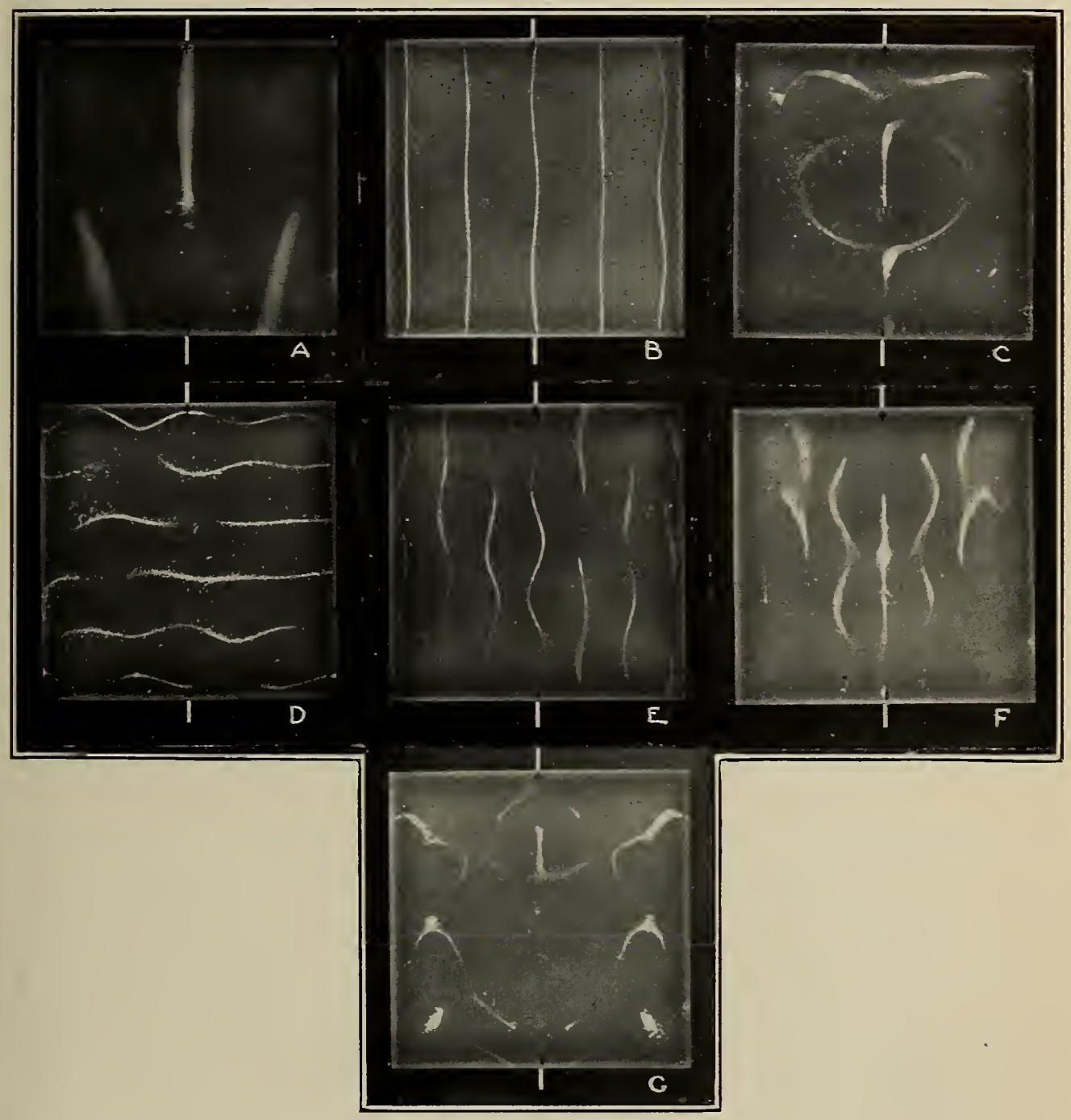

Figure 8.-Thirty-degree plate

36.15 by 36.15 by $4.810 \mathrm{~mm}$.

$D$, 208 kilocycles.

$F, 277$ kilocycles.

$A, 74.0$ kilocycles.

$B, 132$ kilocycles.

$E, 221$ kilocy cles.

$G, 284$ kilocycles. 


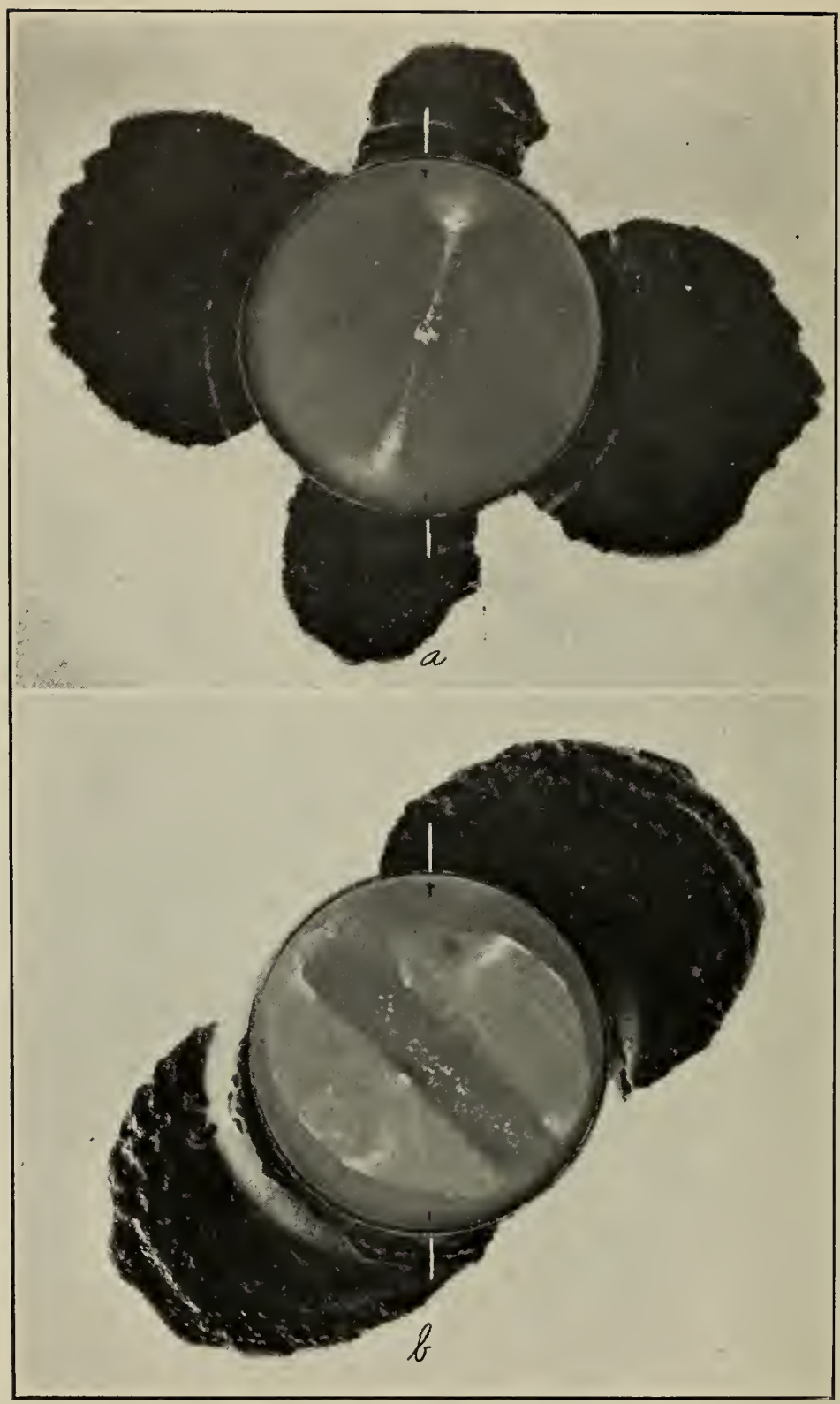

Figure 9.-Zero-degree plate

Diameter $36.03 \mathrm{~mm}$; thickness $4.805 \mathrm{~mm}$. $A$, 75.3 kilocycles; $B, 106$ kilocycles. 
B. S. Journal of Research, RP356

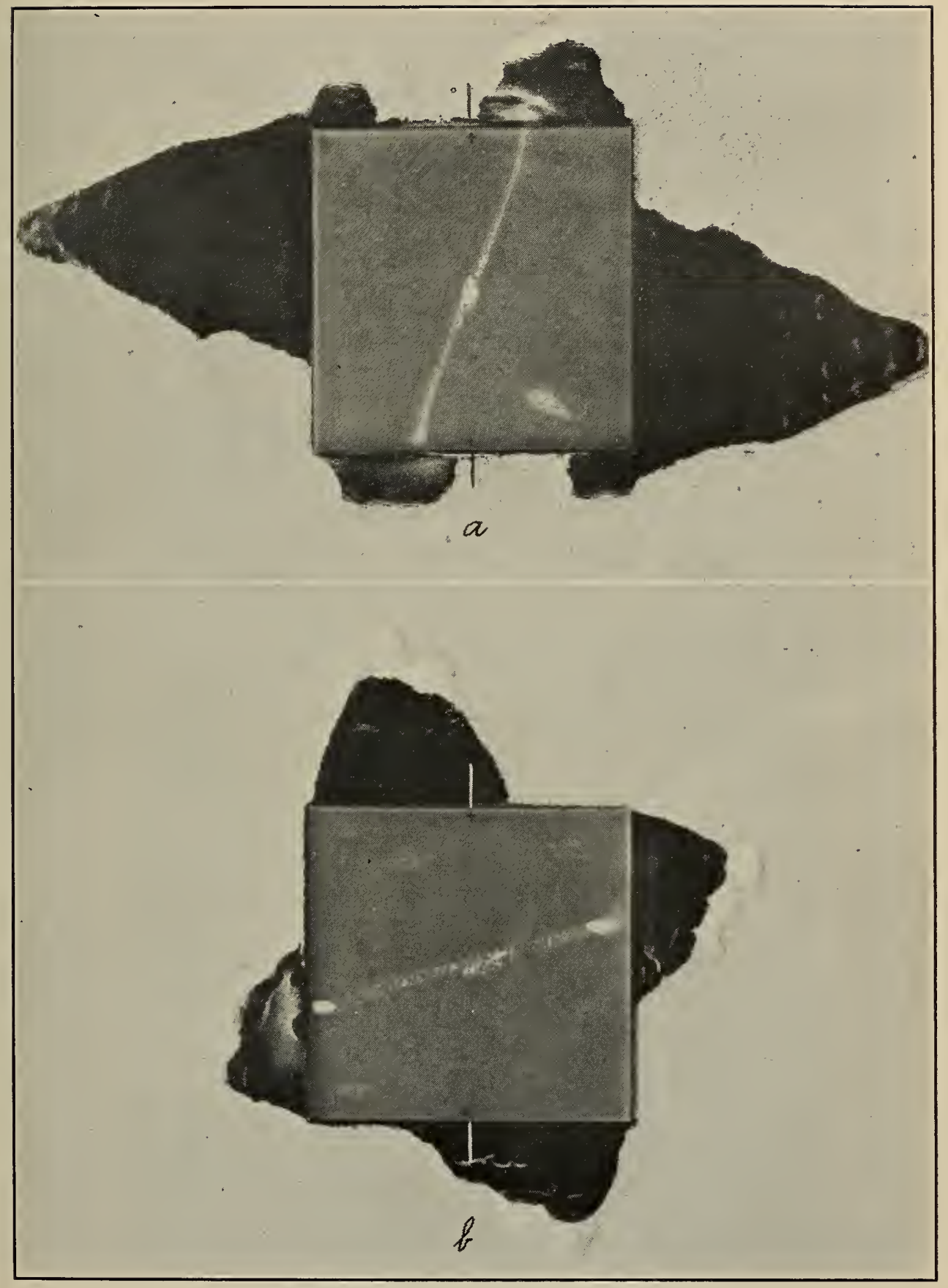

Figure 10.-Zero-degree plate

" optic axis $35.98 \mathrm{~mm}$; $\perp$ optic axis $36.02 \mathrm{~mm}$; thickness $4.810 \mathrm{~mm}$. $A, 66.8$ kilocycles; $B, 83.6$ kilocycles. 
B. S. Journal of Research, RP356

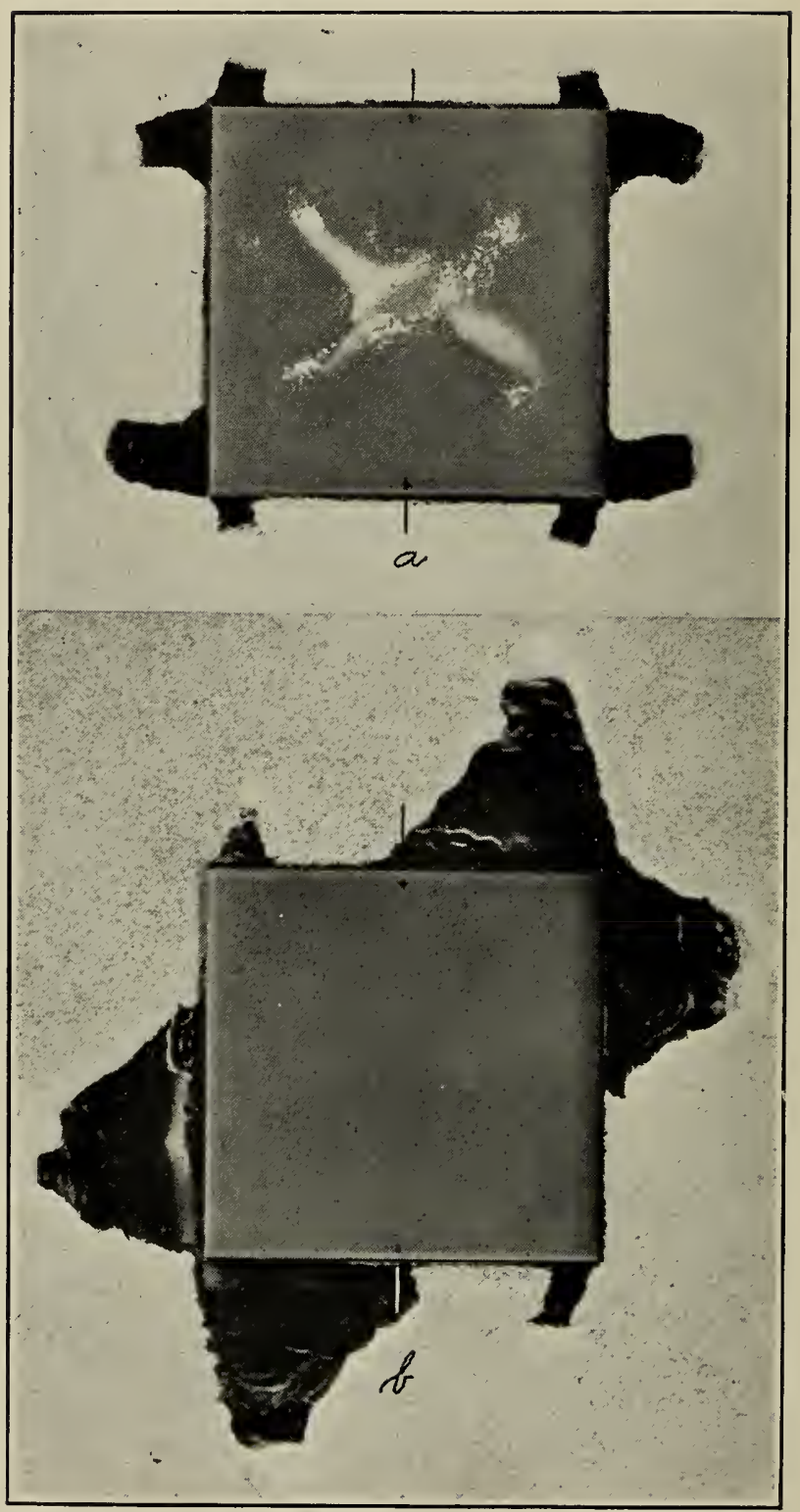

Figure 11.-Zero-degree plate

\| optic axis $35.99 \mathrm{~mm}$; $\perp$ optic axis $36.02 \mathrm{~mm}$; thickness 4.810 mm. $A, 80.4$ kilocycles; $B, 90.0$ kilocycles 


\section{B. S. Journal of Research, RP356}

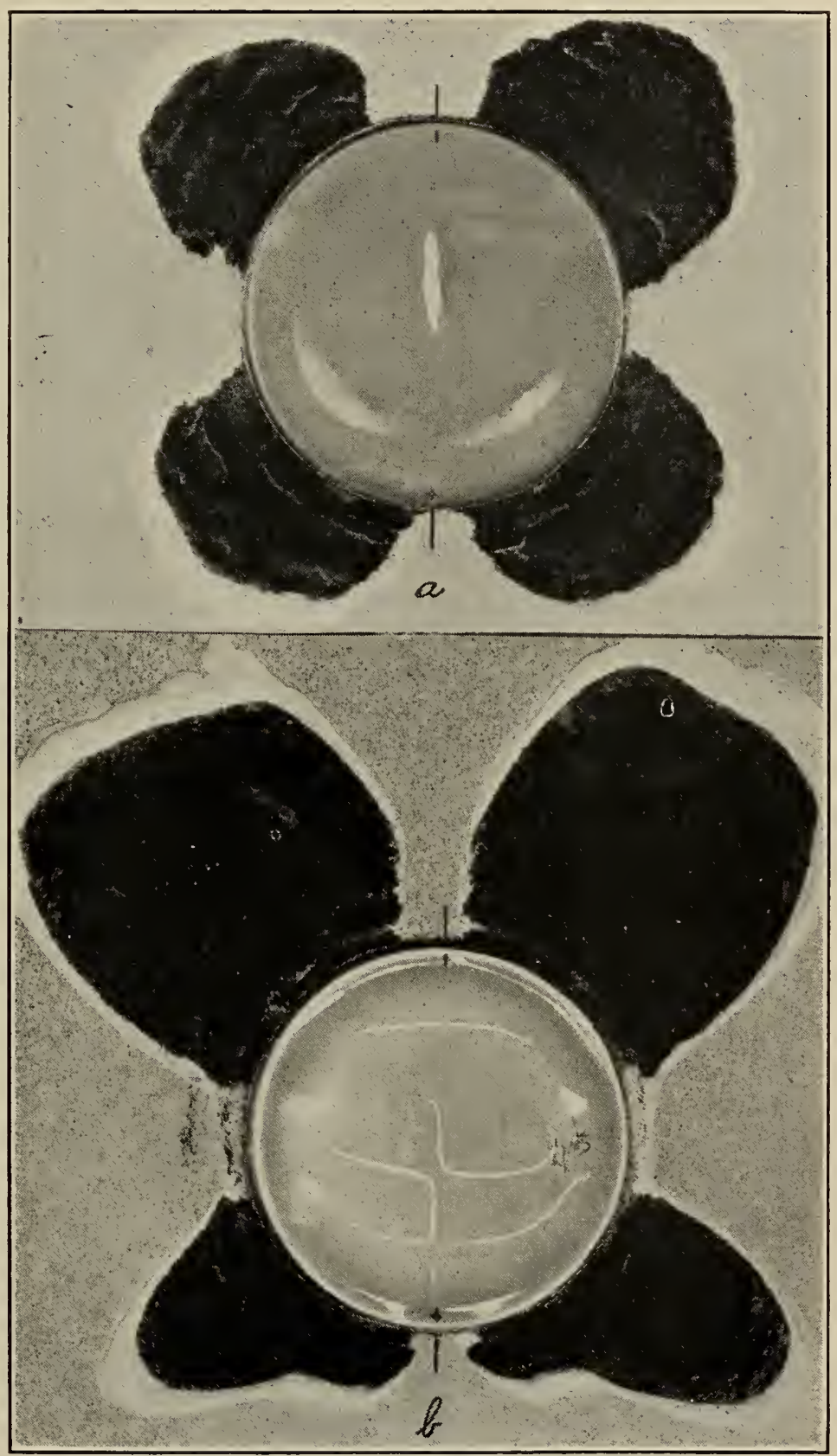

FIgure 12.-Thirty-degree plate

Diameter $36.04 \mathrm{~mm}$; thickness $4.810 \mathrm{~mm}$. $A, 91.2$ kilocycles; $B, 261$ kilocycles. 
B. S. Journal of Research, RP356

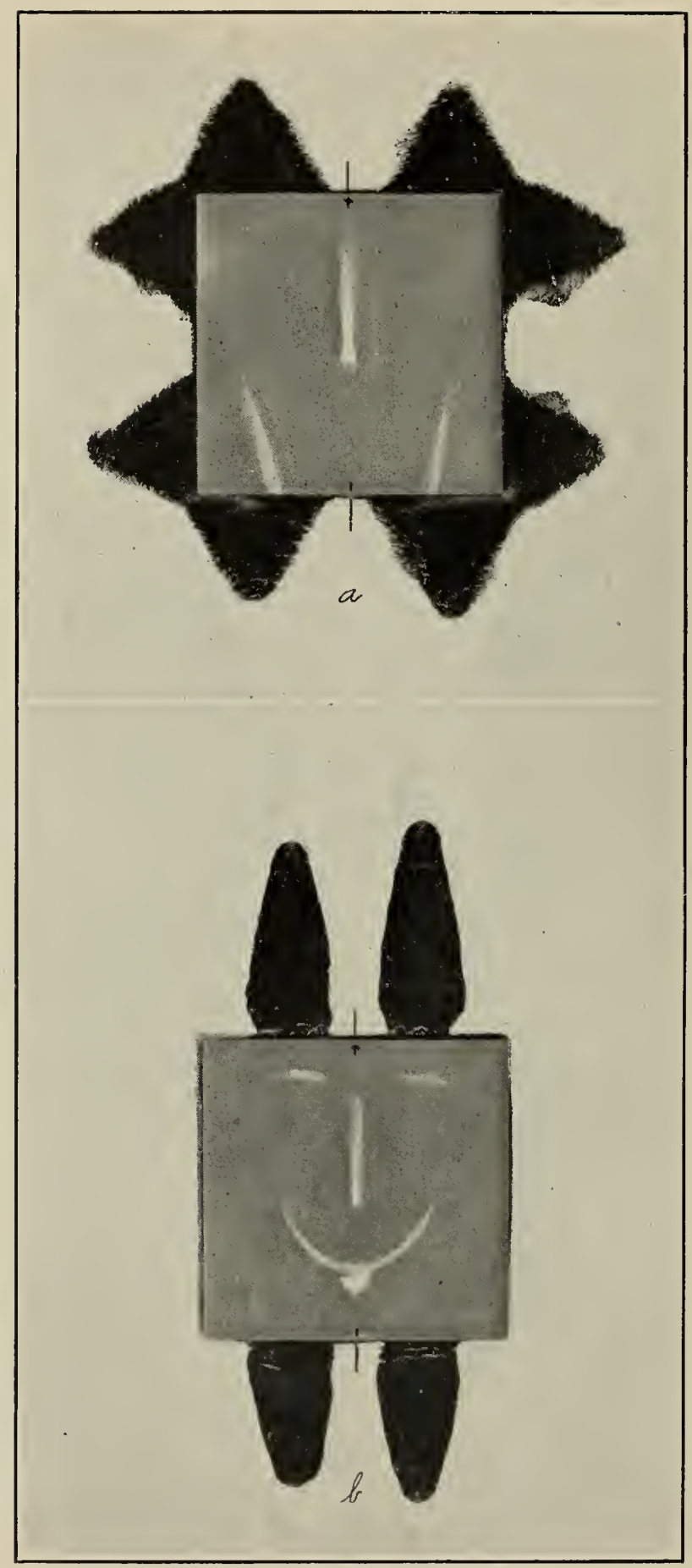

Figure 13.-Thirty-degree plate

36.15 by 36.15 by $4.810 \mathrm{~mm}$. $A, 74.0$ kilocycles; $B, 161$ kilocycles. 


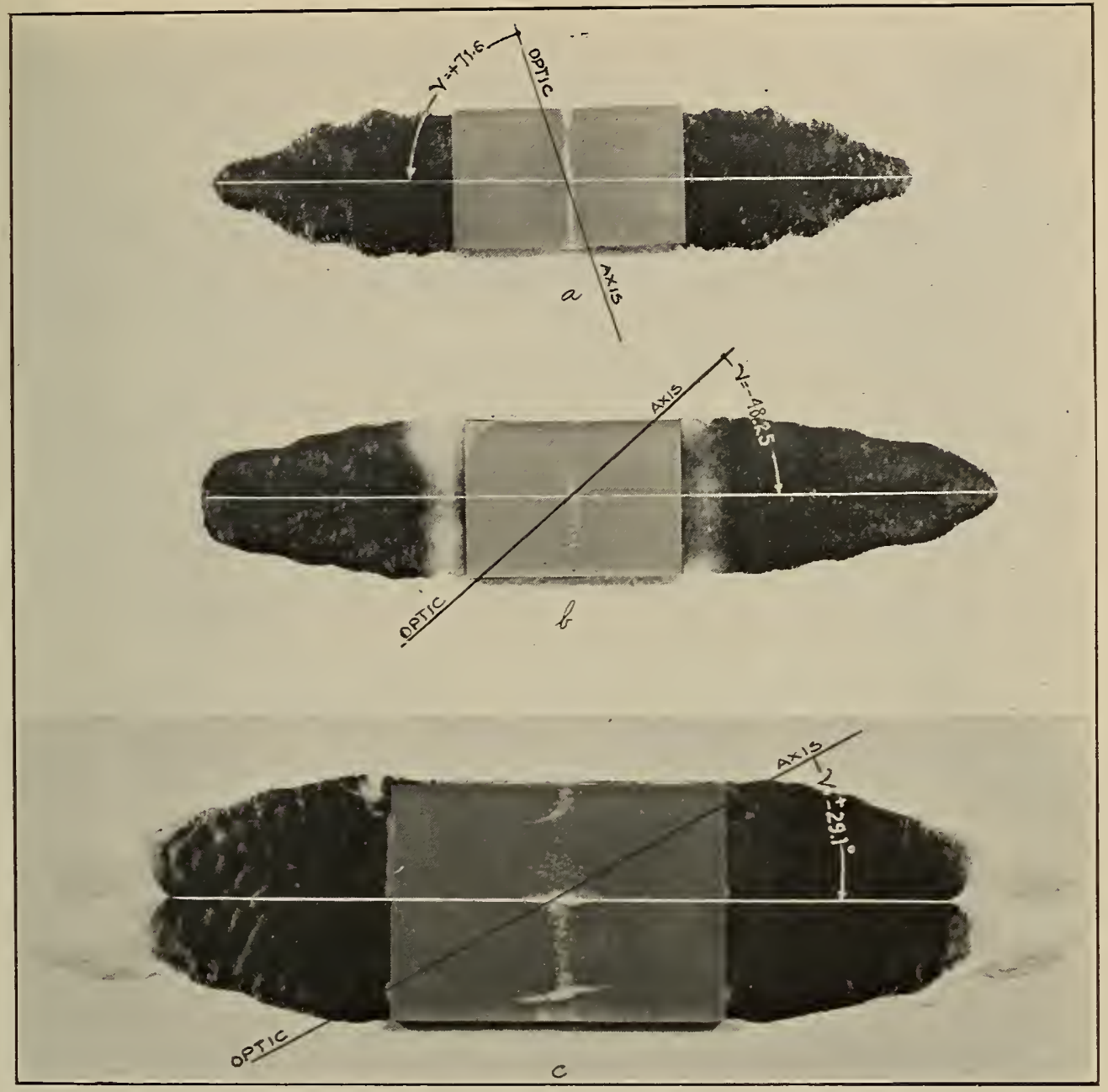

FrguRE 14.-Specially oriented $0^{\circ}$ and $30^{\circ}$

$a, 0^{\circ}$ plate rotated $-18.4^{\circ}\left(\gamma=+71.6^{\circ}\right) ; 30.985 \mathrm{~mm}\left(\gamma=-18.4^{\circ}\right) ; 18.27 \mathrm{~mm}$; thickness $4.81 \mathrm{~mm}$; 82.4 kilocycles. $b, 0^{\circ}$ plate rotated $+41.75^{\circ}\left(\gamma=-48.25^{\circ}\right) ; 28.920 \mathrm{~mm}\left(\gamma=+41.75^{\circ}\right) ; 20.62 \mathrm{~mm}$ thickness $4.84 \mathrm{~mm} ; 120.9$ kilocycles. $c, 30^{\circ}$ plate rotated $\pm 60.88^{\circ}\left(\gamma= \pm 29.12^{\circ}\right) ; 45.165 \mathrm{~mm}$ $\left(\gamma= \pm 60.88^{\circ}\right) ; 31.28 \mathrm{~mm}$; thickness $4.84 \mathrm{~mm} ; 69.7$ kilocycles.

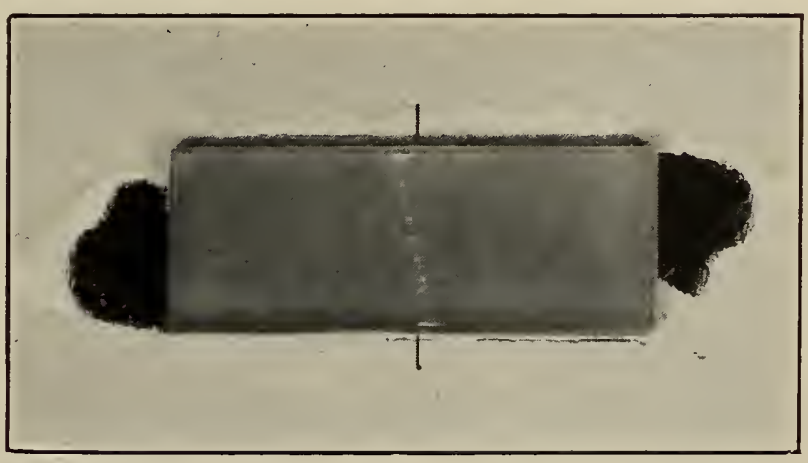

FIGURE 15.-Zero-degree plate of customary orientation 
carried on by means of polarized light by Osterberg, ${ }^{9}$ it is proved beyond doubt that the faces of rectangular plates break up in this manner. Evidence of this nature, which is added to in other studies treated below, is entirely contrary to a statement made, with diagrammatic illustration, by Namba and Matsumura, ${ }^{10}$ to the effect that the faces are distorted as a whole in this mode of vibration.

Only four photographs of interest were obtained of this gas resonance radiation phenomenon when produced by the vibration of square plates. All four are of a $0^{\circ}$ plate. In Figure $2, I$, is shown the only low-frequency pattern obtained before this manner of investigation was concluded. As will be recognized later, this pattern is only indirectly indicative of the type of displacement experienced by the plate. In Figure $2, J$, is shown an interesting pattern, representing what may appear to be a three wave length distribution of a flexural vibration ${ }^{11}$ with waves propagated in a direction perpendicular to both the.optic and electric axes, or along the mechanical axis. Figure $2, K$ and $L$, picture patterns which were observed with a great number of $0^{\circ}$ rectangular plates. These patterns, it will be noticed, resemble the one in Figure $2 C$.

It is possible, but rather improbable, that a thorough-going study of this type of phenomenon might prove profitable. But in its present development this medium of study is much too uncertain. ${ }^{12}$ In an effort to obtain more definite information concerning the modes of vibration of quartz plates, a study was made of patterns formed by lycopodium powder sprinkled on the vibrating faces.

\section{STUDIES OF POWDER PATTERNS FORMED ON THE SURFACE OF PLATES}

In this work the same type of oscillator circuit and electrodes were used. The plates studied were both $0^{\circ}$ and $30^{\circ}$ cuts, square and round. The orientation of these plates is known to be quite accurate in the majority of cases; with certain exceptions they are well within a degree of the stated orientation, probably in most cases within 10 minutes of arc. Purposesly, the first exception is shown in Figure $3, A$. The only other exception of importance is the $0^{\circ}$ square plate. Twinning and inclusions were avoided insofar as it was possible.

H. Osterberg, An Interferometer Method of Observing the Vibrations of an Oscillating Quartz Plate,
Proc. N. A. S., 15, pp. 892-896;1929.
10 See footnote 6, p. 522 .
11 Using the equation $f=\frac{\pi b v}{4 \sqrt{3} l^{2}}\left(\frac{m l}{\pi}\right)^{2}$, which is of a similar type to that used by J. R. Harrison (Piezo-Electric Resonance and Oscillatory Phenomena with Flexural Vibrations in Quartz Plates, Proc. I. R. E., 15,
pp. 1040-1054; 1927), and to that used by S. Jimbo, except for a typographical error (An International Compp. 1040-1054; 1927), and to that used by S. Jimbo, except for a typographical error (An International Comwhere $l$ and $b$ are the greater and lesser actively concerned dimensions of the rod, $v$ is the velocity of propagation, and $\left(\frac{m l}{\pi}\right)$ is the quantity, using Lamb's notation (H. Lamb, Dynamical Theory of Sound), which is equal to $(2 S-1 / 2)+2 \alpha_{s} / \pi$ for the symmetrical case and $(2 S+1 / 2)-2 \beta_{s} / \pi$ for the asymmetrical case, $S$ being an integral number representing the order of the mode, $\alpha_{\boldsymbol{z}}$ being neglible for $S \equiv 3$, and $\boldsymbol{\beta}_{\boldsymbol{z}}$ negligible for $S \mp 2$; and putting $S=3$, for symmetrical case

$$
f=\frac{\overline{5.5}^{2} \pi b v}{4 \sqrt{3} l^{2}}
$$

For $v=5.4 \times 10^{5}, l=3.6$, and $b=0.48 ; f=274 \mathrm{kc}$. This is not in good agreement with the observed value of $177 \mathrm{kc}$, but the discrepancy should not necessarily be considered sufficiently grave to preclude the possibility of the flexural type of vibration.

12 For further evidence of the unsatisfactory nature of this method of study, see the plates in the publications by A. M. Skellett, Modes of Vibration of a Round Plate Cut from a Quartz Crystal, J. Opt. Soc. Am. \& Rev. Sci. Inst., 20, pp. 293-302; 1930; and A Visual Method for Studying Modes of Vibration of Quartz Plates, J. Opt. Soc. Am. \& Rev. Sci. Inst., 17, pp. 308-317; 1928; and see sketches of phenomenon of this nature, appearing in that publication referred to in footnote 6, p. 522, by Namba and Matsumura, 
In Figures 3 to 8 the optic axis is represented quite accurately by the white ruled-in line. One end of the diameter, or in the case of the square plates the line passing through the center of the face parallel to the optic axis, is marked in these photographs by a short black line near the edge of the plate; and the other end by a cross, so that it may be distinguished. When visible in the photographs, these marks may be used as more accurate reference.

\section{(a) ZERO-DEGREE CIRCULAR PLATES}

The orientation of the $0^{\circ}$ circular plate is known to be very accurate. It was cut from optically left rotating quartz, ${ }^{13}$ and is always shown in the photographs with the face uppermost, which becomes positively charged upon application of a normal tensile stress.

As indicated above, the pattern in Figure $3, A$, is shown to illustrate the effect of a small inaccuracy of orientation. The actual orientation of this plate was not verified by measurement. However, experience seems to indicate that had the plate been accurately oriented the pattern would have been that shown in Figure $3, B$. This fact illustrates well the critical nature of patterns formed by lycopodium on the surface of plates whose vibration involves areal dilatation. The difference in frequency of vibration of the two plates shown is due principally to the difference in diameter, rather than to the "pattern" of displacement. This mode is the first mode of a $0^{\circ}$ circular plate in a field parallel to the electric axis. At this mode the displacement is, neglecting second order effects, limited to planes parallel to the face of the plate. Careful study of the motion of the periphery of the two plates under discussion would no doubt show that the two vibrate in a very similar manner, despite the fact that the patterns on their faces differ considerably.

Very little resemblance is to be seen between the surface powder pattern (fig. $3, B$ ) and the glow discharge pattern (fig. 2, $A$ ) for the same mode. The latter, it will be seen, is a poor indication of the nature of the displacements. The powder pattern, on the contrary, is quite informative. The corresponding line to be found on the reverse face forms in a direction parallel to the one shown. Measurement of a series of these patterns indicates that this line is inclined $17^{\circ} 30^{\prime}\left( \pm 1^{\circ}\right)$ from the optic axis. Reference to Figure 23, Appendix II, will show that if this angle is taken in the negative sense, the line is closely perpendicular to the direction of the minimum of Young's modulus for the $0^{\circ}$ plane. The plate shown in Figures $3, B$, to $4, I$, is of optically left rotating quartz, and its upper face, upon which the patterns are formed in all cases, is the one that becomes negatively charged upon application of a normal tensile stress. This, as explained in more detail in Appendix II, requires that the angle between the optic axis and this line be negative in sense in order to correspond to conventions upon which the given curves of Young's modulus are based. Thus the "nodal" line is closely perpendicular to the direction of the minimum of Young's modulus.

However, this line is not a nodal line in the strict sense of the word. The powder forming it runs outward, spreading before reaching the periphery of the plate. Thus it appears that the line marks a node of

${ }^{13}$ As viewed when looking toward the light source. 
only those displacements in the plane of the face which are normal to the line. The reason for the outward motion of the powder will be made apparent in the description of patterns formed by air currents set up by the oscillation of the plate.

In Figure 3, $C$, is shown a very similar pattern. As in the preceding case, the line on the lower face is found to lie in a direction parallel to the one on the upper face. Here, however, the line is inclined approximately $67^{\circ}$ from the optic axis, in a negative sense as before. Young's modulus for the $0^{\circ}$ plane will be seen to pass through a maximum at $\gamma=+10^{\circ} 50^{\prime}$. Although the correspondence between this and the normal to the line in the pattern is not close, relation between the two will be shown to be quite probable. This mode is one of relatively weak response.

Coming now to Figure 3, $D$, a pattern of somewhat different nature is shown. Judging from the formation of the dust pattern in this case, this line is strictly a nodal line; there is no apparent movement of the powder forming it. During formation the powder moves perpendicularly away from it toward the periphery. The powder stops on reaching a midway region where it assumes a dancing motion. The line in this case is found to be between $-43^{\circ}$ and $-44^{\circ}$ from the optic axis. This direction is quite closely perpendicular to the direction of maximum Young's modulus, $\gamma=-48^{\circ} 15^{\prime}$. The mode accompanied by this pattern is the second mode of vibration of $0^{\circ}$ circular plates. It is the same as that accompanied by the discharge pattern seen in Figure 2, $B$. The optic axis was not very accurately determined in this latter case, as will be evident from a comparison of the two photographs. It is quite certain, however, that the diameter through the center of the discharge corresponds to the nodal line formed by the lycopodium for this mode. Either the plate in the former case was of optically right rotating quartz or its upper face is the one which would become positively charged upon application of a normal tensile stress. These deductions may be made, knowing, as in both the above cases, that the line forming on the reverse face takes a direction parallel to the line on the upper face.

At $125 \mathrm{kc}$ the interesting pattern shown in Figure 3, $E$, appears. The amplitude with which the plate responds at this mode is very small. This mode may be one of flexural vibration. It appears to have maximum displacement in the direction of the optic axis. With some plates, of practically the same dimensions, this pattern develops into complete rings.

Figure 3, $F$, shows the pattern accompanying a mode at which this plate responds with fairly large amplitude at $136 \mathrm{kc}$. At both ends of the two figures composing this pattern the powder revolves rapidly. It is interesting to note that these figures are roughly perpendicular to the optic axis. A symmetrical pattern for this mode is found only in a few plates.

In Figure 3, $G$, appears the pattern observed at $146 \mathrm{kc}$. In this the powder takes on a revolving motion at the center. With some plates this pattern is altered to resemble closely that shown in Figure 6, $C$, which is produced on a $30^{\circ}$ plate at a frequency less than a kilocycle different from that of the former. It is quite probable that the plates on which the pattern is altered would be found to be inaccurately oriented with respect to the electric axis. 
The principal difference between patterns shown in Figures $3, H$ and $I$, lies in the angle of inclination. Both modes of vibration are fairly strong. The one responding at $169 \mathrm{kc}$ was found the more vigorous.

The pattern shown in Figure 3, $J$, accompanies a stronger oscillation than those accompanied by patterns in Figure $3, H$ and $I$. The strength of this oscillation is about the same as the $136 \mathrm{kc}$ mode, the pattern for which is shown in Figure $3, F$.

The mode whose pattern is shown in Figure $3, K$, is, perhaps, a little stronger than that accompanied by the pattern in Figure $3, F$, while that whose pattern is shown in Figure $3, L$, is a little weaker. The pattern shown in Figure $4, A$, is again stronger, being nearly equivalent in response to the modes accompanied by patterns shown in Figures $3, F, J, K$.

The mode represented by the pattern in Figure 4, $B$, on the other hand, is quite weak. The rest of the modes whose patterns are shown, however, are stronger.

Both modes represented by patterns in Figure 4, $C$ and $D$, are about equivalent in strength to those whose patterns are shown in Figures 3 , $F, J, K$, and $4, A$. The larger spots in Figure $4, D$, are regions in which the powder revolves rapidly.

The figure for the $400 \mathrm{kc}$ mode shown in Figure 4, $E$, is quite representative. Whereas some of the patterns found above $146 \mathrm{kc}$ for the particular plate used are not always to be found with all plates, this figure nearly always occurs.

In Figure $4, G$ and $H$, are to be seen two patterns of the same mode of vibration. This mode is the third mode of $0^{\circ}$ circular plates. The displacement is principally in the direction of the thickness, which makes it difficult to obtain any sort of a powder pattern. A strong current of air is given off the face of the plate causing the powder to be blown away. An unmistakable symmetry of form will be noticed in this pattern. Moreover, this pattern constitutes very good evidence of the breaking up of the surface, mentioned above, during this oscillation. It has been noticed that the pattern accompanying this oscillation is quite critical with respect to dimensional ratio and accuracy of orientation.

The pattern in Figure 4, $I$, accompanies quite a vigorous vibration. In it is seen some tendency toward symmetry. The fact that the pattern is not entirely symmetrical may have bearing on the fact that this oscillation is weaker than the one appearing at a slightly lower frequency.

It was found that the four lower modes shown (fig. 3, $B, C, D, E$, and $F^{\prime}$ ) remain relatively unchanged in manner of response through a wide range of the ratio of the diameter to the thickness.

For many modes, particularly those occurring at frequencies about midway between the lowest and highest frequencies concerned here, straight lines formed on the periphery of the plate, parallel to the axis of physical or geometric symmetry of the plate, different modes involving different numbers and spacing thereof. In some of the patterns of more eleaborate design these lines on the periphery of the plate curve around in an attempt to complete the pattern, instead of being straight and parallel. 
(b) ZERO-DEGREE SQUARE PLATES

As already mentioned, the orientation of the $0^{\circ}$ square plate used in these studies is not very accurately known. It is probably within $2^{\circ}$ of the proper orientation. It is of optically right rotating quartz, and that face which becomes negatively charged upon application of a normal tensile stress is always uppermost in the photographs. Thus the orientation with respect to the observer, of the elastic characteristics of this plate is similar to that of the circular plate.

The first pattern is of considerable interest, a "nodal" line within less than $5^{\circ}$ of the direction taken by a similar line in the case of the circular plate. Not only does the line in Figure 5, $A$, correspond closely in direction to that in Figure $3, B$, but it also resembles the latter in manner of formation; the powder forming the line moves outward, finally spreading as it did on the circular plate.

A second correspondence is found between the pattern in Figure 5, $B$, and that for the circular plate shown in Figure $3, C$. In this case the angle $\gamma$ is about $+73^{\circ}$ for the square and about $+67^{\circ}$ for the circular plate. It will be noticed that in the case of the square plate the frequencies of the two modes are about as nearly inversely proportional to the square roots of Young's modulus in directions perpendicular to the corresponding "nodal" lines as they are in the case of the circular plate. This relation which appears to be a coincidence is explained, no doubt, by the fact that the intercepted perdendicular bisectors of the "nodal" lines in the two cases for the square plate are about of equal length. This fact should be by no means difficult to accept considering that the "nodal" line which forms on the circular plate at the lower frequency is inclined to the optic axis by an angle which is about equal to that with which the "nodal" line accompanying the higher frequency mode is inclined to the normal to the optic axis. Although dependent upon the former and latter facts, and therefore again an apparent coincidence, it should be interesting to note that the ratio of the lower frequency of the circular plate (fig. 3 , $B$ ) to that of the square plate (fig. $5, A$ ); that is, $\frac{75.3}{66.8}=1.13$, is practically equal to the corresponding ratio of the higher frequencies. $\frac{93.5}{83.6}=1.12$.

When this series of patterns was photographed no presentable pattern could be obtained for that mode of response of the square plate corresponding to the mode of a circular plate whose pattern is shown in Figure $3, D$. However, such a mode exists; the frequency at which it responds is $90 \mathrm{kc}$. Description of this mode will be reserved for a succeeding section, as will be the discussion of an additional pattern not obtained during the photographing of this series, which may be found in Figure 11, $A$.

Figure 5, $C$, shows the powder pattern corresponding to the gas resonance radiation pattern in Figure $2, J$. Judging from the distance of the two outer lines from the edges of the plate the lines marked by the powder are probably nodal in nature, indicating that lines marked by the glow discharge in Figure $2, J$, are of an antinodal nature.

At $202 \mathrm{kc}$ is found the pattern shown in Figure 5, D, and at $204 \mathrm{kc}$ the less elaborate pattern in Figure $5, E$. The plate responds quite 
feebly at this latter mode of vibration. In Figure $5, F$, is shown the peculiar but symmetrical pattern found at $210 \mathrm{kc}$. At this frequency the plate vibrates relatively strongly.

In Figure $5, G$ and $H$, are to be seen patterns ' which appear as though they might accompany flexural vibrations. These modes do not respond very strongly.

Just as in the case of the circular plate, straight lines were found to form on the edges perpendicular to the faces of the square plate varying in number and disposal with the modes which they accompany, while for some modes curved lines formed on the edges in a manner tending to complete the pattern forming on the face.

\section{(c) THIRTY-DEGREE CIRCULAR PLATES}

The $30^{\circ}$ plate shown in this series of photographs was cut from optically left rotating quartz. It is in all cases shown in such a position that the edge to the left is the one that would become positively charged upon application of a tensile stress along the electric axis. Its orientation is known to be very accurate. The white ruled-in line as before represents the optic axis. The plate itself is marked in the same manner as were both the square and round $0^{\circ}$ plates, with a short line and a cross representing the optic axis.

It is common knowledge that the strongest mode of vibration of $30^{\circ}$ plates responds at a frequency about two-thirds that at which is found the strongest response of $0^{\circ}$ plates of the same dimensions. The type of vibration occurring at the frequency of strongest vibration of $30^{\circ}$ plates is as pointed out by Cady, ${ }^{14}$ essentially of a shearing nature. When a $30^{\circ}$ plate is caused to oscillate at this frequency in the usual type of vacuum tube circuit, beat notes may usually be heard in phones placed in the circuit, indicating that several modes of vibration are being sustained simultaneously.

Comparable with the lower modes of strong response found for $0^{\circ}$ circular plates, there is found for $30^{\circ}$ plates the mode whose pattern is to be seen in Figure 6, A. A certain amount of importance is to be attached to this mode of vibration, for it may be executed by circular plates of practically any orientation. The frequency at which the mode responds differs for the different orientations, but the pattern formed remains quite unchanged. It was even found to be executed by a plate cut accurately perpendicular to the optic axis. The pattern on the reverse face, as would be expected, is the duplicate of the one shown, with an orientation that may be described as that taken by the latter upon rotation through $180^{\circ}$ about the electric axis.

Although the patterns shown in Figure $6, B$ and $C$, are quite similar, and occur at very nearly the same frequency, they appear to belong to different clases or series. The patterns shown in Figures $6, G$, and $7, F$, appear related to that shown in Figure $6, B$. The modes accompanied by these three patterns are all quite strong in response, the strength increasing with frequency. The one of highest frequency is one of the most vigorous modes of the plate. The mode accompanied by the pattern in Figure 7, $C$, appears to belong to the same series as that whose pattern is shown in Figure $6, C$. These two modes are quite weak. The mode whose pattern is seen in

14 W. G. Cady, A Shear Mode of Crystal Vibration (abstract), Phys. Rev., 29, p. 617; 1927. 
Figure $6, E$, is strong, and its pattern appears to be a higher development of that in Figure $6, A$, accompanying the mode already described, which is also of strong response. Moreover, the frequency of the mode whose pattern is shown in Figure $6, E$, is very nearly double that whose mode is shown in Figure $6, A$. Correspondingly, patterns in Figures $6, J$, and $7, E$, appear as developments of that in Figure $6, D$, and that in Figure $7, A$, as a development of that in Figure $6, H$, the modes accompanied by the latter two patterns being quite strong.

At the modes accompanied by patterns shown in Figure $6, L$ and $F$, the plate responds quite readily while at those whose patterns are shown in Figure $6, I$ and $K$, the response is weak as it is at the mode whose pattern is shown in Figure $7, B$.

When the particular $30^{\circ}$ plate used in these experiments is caused to oscillate in the customary piezo-oscillator circuit, it responds simultaneously at all three modes whose patterns are shown in Figure $7, F, G$, and $H$. In plates of approximately the same dimensions, the mode whose pattern is shown in Figure $7, I$, is found to be sustained simultaneously with the other three in the ordinary circuit.

\section{(d) THIRTY-DEGREE SQUARE PLATE}

The particular plate used in obtaining the series of photographs of patterns formed on the face of $30^{\circ}$ square plates during vibration, was cut from optically right rotating quartz. In all cases the plate is shown in a position such that the edge that becomes positively charged upon application of a normal tensile stress is to the right.

As might be expected from the behavior of $0^{\circ}$ square and round plates at the lower frequencies, there is found for the lowest mode of vibration of a $30^{\circ}$ square plate a pattern resembling that accompanying the lowest mode of a $30^{\circ}$ circular plate. Resemblance between patterns in Figures $8, A$, and $6, A$, is undeniable.

In Figure $8, B$, is shown a pattern very similar to that shown in Figure $5, C$. Both appear as though they may be formed by a flexural type of vibration. ${ }^{15}$

At $161 \mathrm{kc}$. was found the pattern shown in Figure 8, C. Similarity between this pattern and the one for the $30^{\circ}$ circular plate shown in Figure $6, D$, is quite evident. Incidently it will be noted that the frequencies are the same. The square plate oscillates quite strongly at this frequency.

At $208 \mathrm{kc}$ appeared the pattern $\mathrm{in}^{\mathrm{F}} \mathrm{Figur}, \mathrm{D}$. This pattern is similar to some extent to the one referred to above and shown in Figure $5, C$, except that the "nodal" lines are roughly perpendicular to the optic axis. That the two are of similar nature despite the fact that the lines are fairly straight in one case and not in the other is indicated by the fact that the frequencies of the two are quite closely proportional to the half power of Young's modulus for the two directions.

In Figure $8, E$, is the pattern produced by a similar type of vibration of higher order. At this and the mode previously discussed the plate responds quite readily in the circuit used.

15 This would correspond to the second order asymmetric case, for which $S=2$, making $\left(\frac{m l}{\pi}\right)=4.5$ in the equation given in footnote 11, p. 523 . Using this, $f=183 \mathrm{kc}$, which is much higher than the observed frequency of $132 \mathrm{kc}$.

$68723-31-8$ 
At $284 \mathrm{kc}$ the square plate responded quite vigorously with the pattern shown in Figure $8, G$. The pattern in Figure $8, F$, accompanied also a strong response.

Lines on the edges of both circular and square $30^{\circ}$ plates were found to accompany most patterns of intermediate modes. These lines resemble those for the $0^{\circ}$ plates, with the difference that in this latter case the straight lines perpendicular to the faces appeared to predominate, whereas in the case of the $30^{\circ}$ plates the curved ones which tend to complete the facial patterns, were found more frequently.

(e) COMMENTS CONCERNING SURFACE POWDER PATTERNS

In Figure 23, Appendix II, is shown reflected symmetry of the elastic modulus in the XZ-plane with respect to both the optic and electric axes. On the other hand, the elastic modulus in the YZplane shows only an axis of symmetry, the covering operation being rotation through $180^{\circ}$. This might lead one to expect twofold symmetry of patterns on $30^{\circ}$ plates, and merely an axis of symmetry in the case of patterns on $0^{\circ}$ plates. In fact, in the case of $0^{\circ}$ plates, the axis of symmetry is found present with hardly an exception. However, in the case of $30^{\circ}$ plates, only reflected symmetry with respect to the optic axis is found. The fact that the patterns show no symmetry with respect to the electric axis may be attributed to the lack of reflected symmetry of Young's modulus in the YZ-plane.

Thus, it is seen that while the patterns may be very difficult of interpretation, and must be analyzed with the utmost caution, they nevertheless appear to involve nothing in discord with the well established elastic structure of quartz. And this is indicative, to some extent at least, that electric forces play only a minor part in the formation of these patterns. It is possible that the critical nature of some may be caused by the action of electric forces, but there is no apparent reason for such an effect.

Patterns of this nature are obtainable in number without end. Those reproduced and described here constitute only a small part.

\section{STUDIES OF POWDER PATTERNS FORMED BY AIR CURRENTS EMANATING FROM THE PERIPHERY OF PLATES}

(a) ZERO-DEGREE CIRCULAR PLATES

As is well illustrated by experiments carried on by Meissner, ${ }^{16}$ plates when driven with sufficient amplitude create quite strong disturbances in the surrounding air. The air currents set up in this manner may be employed as a means of studying the vibrations of plates. These currents, when the plate is excited at its lower frequency modes of vibration, emanate from its periphery. If the plane of the lower electrode is extended for some distance beyond the periphery and a layer of lycopodium is sprinkled on this extended surface, the air currents will cause some of the powder to be displaced. In Figure $9 A$, may be seen the effect on lycopodium sprinkled around a zero-degree circular plate when it is caused to vibrate at $75.3 \mathrm{kc}$. At this excitation frequency, it will be recalled, is found the first mode of vibration of this $0^{\circ}$ plate. It will be recognized by its surface powder pattern,

${ }_{16}$ A. Meissner, Piezo-Electric Crystals at Radio Frequencies, Proc. I. R. E., 15, pp. 281-296; 1927; or ZS. f. 'Techn. Phys., 7, pp. 585-592; 1926. 
which is the same as that shown in Figure $3, B$. The reason for the outward motion of the powder forming the "nodal" line is now apparent. In the general direction of the line is seen the maximum of a secondary antinodal region of areal displacement.

In Figure $9, B$, is shown the air current pattern formed at the second mode of a $0^{\circ}$ plate, illustrating the difference between the two modes of vibration. It is seen that the line in this case must be quite strictly a nodal line.

Meissner ${ }^{17}$ shows photographs of this nature. His, however, appear to be the results of the two modes superposed.

\section{(b) ZERO-DEGREE SQUARE PLATES}

The patterns shown in Figure $5, A$ and $B$, for $0^{\circ}$ square plates, are shown again in Figure 10, $A$ and $B$, in company with the corresponding air current pattern. Comparison of Figures $9, A$ and $10, A$, show that the modes of vibration involved are quite similar.

In Figure 11, $B$, appears the air current pattern for the mode corresponding to the second mode of $0^{\circ}$ circular plates. No presentable surface powder pattern could be obtained for this mode as was stated above. The air current pattern, in itself, however, is quite convincing evidence of the correspondence.

The air current and surface patterns for the mode whose ionization pattern is shown in Figure 2, $I$, are presented in Figure 11, $A$. Comparison of the two shows little similarity. The gas resonance radiation apparently marks a nodal region in this case, while in others it is found to mark antinodal regions.

\section{(c) THIRTY-DEGREE CIRCULAR PLATES}

The air current pattern for the mode of vibration shown in Figure $6, A$, together with the surface pattern, is to be seen in Figure 12, $A$. In company with the air current pattern the surface pattern takes on a more rational appearance. As previously explained, the pattern on the reverse face when seen through the plate would tend to complete the symmetry. It might be pointed out here that Young's modulus for the plane of a $30^{\circ}$ plate shows a maximum at $\gamma= \pm 29^{\circ} 6^{\prime}$. Whether the maximum radial displacement takes place at these angles as might be expected from observations of the behavior of $0^{\circ}$ circular plates, or at $\gamma= \pm 45^{\circ}$ as one might be led to expect by the air current pattern shown, is not clear; it will probably be found somewhere between.

A somewhat better idea of the type of displacement involved in modes of the apparent series (figs. $6, D$ and $J$, and $7, E$ ), may be gained from Figure 12, $B$. As in the case of surface patterns on $30^{\circ}$ plates, rotation of the plate about the electric axis through $180^{\circ}$ would result in the same pattern. But rotation of the plate by the same amount about either the optic or mechanical axes would cause an apparent rotation of the air current pattern through an equal angle about the electric axis.

\section{(d) THIRTY-DEGREE SQUARE PLATES}

Fundamental similarity is again shown between modes of vibration in square and circular plates of quartz, by a comparison of Figure 13, $A$, with Figure 12, $A$. Of course, patterns caused by air currents are

${ }^{17}$ A. Meissner, Untersuchung über Pyro- und Piezo-Elektrizităt. Die Naturwissenschaften, 17, pp. 2531; 1929; and in the publication of his, referred to in footnote $5, \mathrm{p}, 522$. 
not always to be interpreted directly. But particles in the corners of the square plate are apparently displaced principally along a diagonal, for this mode of vibration.

The air current pattern for the mode whose surface pattern was first shown in Figure 8, $C$, is given in Figure 13, $B$. It shows that the displacement is principally in the direction of the optic axis.

Air current patterns for the different cuts and shapes may be obtained in large numbers. Only a few are shown and discussed here.

(e) SPECIALLY ORIENTED $0^{\circ}$ AND $30^{\circ}$ CUT RECTANGULAR PLATES AND RODS

As previously indicated, results of these studies show that the directions of maximum displacement in several of the low frequency modes of $0^{\circ}$ circular plates are to be found nearly parallel to the direction of some one of the critical values of Young's modulus, and to have similar tendencies in low-frequency modes of $0^{\circ}$ rectangular plates. Acting upon this information, four rectangular plates were cut, three $0^{\circ}$ and one $30^{\circ}$, each with length parallel to one of these critical directions. ${ }^{18}$ Two of the $0^{\circ}$ plates and the one $30^{\circ}$ plate are shown in Figure 14, together with the pattern of the mode found for each in which the displacements are principally parallel to the lengths as indicated both by the fact that the "nodal" lines form perpendicular to the lengths and by the nature of the accompanying air current patterns. The remaining $0^{\circ}$ plate, which was cut with length parallel to the critical direction of Young's modulus in the $0^{\circ}$ plane to be found at $\gamma=+10^{\circ} 50^{\prime}$, could not be caused to vibrate with sufficient amplitude to produce an air current pattern. However, a similar simple mode of vibration was found for this plate, as evidenced by the nodal line perpendicular to its length.

In Figure 15 is shown a $0^{\circ}$ rectangular plate of the conventional orientation, in company with the pattern caused by vibration at the one of its modes having principal displacements most nearly parallel to its length. The "nodal" line forms, as shown, in a direction inclined to the edges. The displacements experienced by this plate are thus seen to be of a more complex nature than those depicted in Figure 14.

Referring again to Figure 14, if the frequency in any one of the three cases shown were squared and multiplied by the square of twice the greatest dimension of the corresponding plate and by 2.654 , the density in grams per cubic centimeter, there would result, as shown below, a value which corresponds very closely to the value of Young's modulus for the direction parallel to this greatest dimension. The same is true of the $0^{\circ}$ plate which was so oriented in cutting that its greatest dimension is parallel to the direction, $\gamma=+10^{\circ} 50^{\prime}$, for which no air current pattern is shown. This plate is 32.71 by 22.70 by 4.81 $\mathrm{mm}$, and its frequency of response at that mode involving a "nodal" line perpendicular to its greatest dimension, is $95.4 \mathrm{kc}$. The operations indicated above for these four cases give, in kilomegabaryes $\left(10^{9}\right.$ dynes per $\left.\mathrm{cm}^{2}\right) 692,1,035$, and 1,298 for the specially oriented $0^{\circ}$ plates, and 1,051 for the specially oriented $30^{\circ}$ plate. The corresponding values of Young's modulus are, as given in Appendix II, respectively, 691, 1,014, 1,285, and 1,045, in the same units. The

is $\Lambda$ patent was taken out by the Telefunken Co. (Patent No. 294174) for orientations of quartz plates, presumably $0^{\circ}$, such that edges would be parallel and perpendicular to the directions $\gamma=48^{\circ}$ and $70^{\circ}$, as reported in the Wireless World, May 29, 1929. 
former values, it will be noticed, are in each case slightly larger, but all are within 3 per cent.

In order to determine how closely the length and frequency of rods cut in these various critical directions would agree with the computed values of Young's modulus (which, of course, are based on measurements of certain elastic constants, as explained in Appendix II), rods of square cross section were cut from each of these plates in such a manner as to leave the length and thickness dimension undisturbed. The frequencies of these rods were found to be 82.7, 95.2, 119.7, and 69.6 kc. With the given lengths results are obtained which agree with the theoretical critical values of Young's modulus given above within less than 2 per cent. These results are to be found entered in Table 1 , column 5. In column 6 appear corresponding values which have been approximately corrected for lateral effects. The arbitrary correction factor used, the nature of which is explained at the bottom of the table, reduces to that proposed by Chree ${ }^{19}$ when $\sigma_{1}$ is placed equal to $\sigma_{2}$; in fact, this is about the only justification that may be advanced for its use, except that it would result in a little closer approximation, in all probability, than would the one proposed by Chree into which some average value of $\sigma$ is substituted. ${ }^{20}$ The corresponding computed values of Young's modulus are to be found in column 7 . In column 8 are given the per cent deviation between values in columns 6 and 7 .

It is interesting to note in this respect that the length and frequency of three of the longer $0^{\circ}$ rods used by Cady give values agreeing no closer than from 5 to 14 per cent, when corrected for lateral effects, with the computed value of Young's modulus in the direction of their length, namely, 770 kilomegabaryes. One ${ }^{21}$ of these was 12.02 by 2.16 by $1.08 \mathrm{~mm}$ with a frequency of $235.9 \mathrm{kc}$. A second, ${ }^{22}$ whose frequency was $91.66 \mathrm{kc}$, measured 30.3 by 2.64 by $1.23 \mathrm{~mm}$. The third, ${ }^{22}$ resonating at $89.87 \mathrm{kc}$, measured 30.7 by 4 by $1.4 \mathrm{~mm}$. These all have one lateral dimension about 10 to 12 per cent of the length, while the other lateral dimension is much less. Operations similar to those above give the results, respectively, 880, 819, and 808 kilomegabaryes. The ratios of the greater of the two lateral dimensions to the length dimension are approximately 18, 9, and 13 per cent, respectively.

Measurements of the maximum radial displacement for the first mode of a $0^{\circ}$ circular plate gave a result $1^{\circ} 50^{\prime}$ greater than the predicted angle of the minimum value of Young's modulus. This indicates a possibility of a discrepancy between actual and predicted direction of this minimum. In order to verify the angle at which the actual minimum occurs, three $0^{\circ}$ rods were cut, all of the same length, with such orientations that their lengths are parallel, respectively, to the three directions, $\gamma=+67.31^{\circ},+71.56^{\circ},+73.74^{\circ}$. The fundamental frequencies at which these rods respond proved to be, respectively, 79.117, 79.007, and $79.242 \mathrm{kc}$. The first of these frequencies is 0.30 per cent and the third 0.14 per cent higher than the second. Assuming for each the same correction for lateral inertia

19 C. Chree, On Longitudinal Vibrations, Quart. J. Math., 23, pp. 317-342; 1889.

${ }^{20}$ It might be well to explain here that although a correction factor of this nature can not be considered adequate or appropriate for rods whose lateral dimensions are as proportionately great as some given in the table, its use should nevertheless place the values given in column 5 on a more compatible basis.

${ }_{21}$ W. G. Cady, An International Comparison of Radio Wave-Length Standards by Means of PiezoElectric Resonators, Proc. I. R. E., 12, pp. 805-816; 1924 .

${ }_{22}$ W. G. Cady, Piezo-Electric Standards of High Frequency, J, Opt. Soc. Am. \& Rev. Sci. Inst., 10, pp. 475-489; 1925 . 
effects, and using the computed values of Young's modulus, the frequency of the first rod would be 0.26 per cent and the frequency of the third 0.07 per cent greater than that of the second. From this we may conclude that the predicted and actual angles of the minimum of Young's modulus agree within a degree. The dimensions of the three rods, which are all quite accurately oriented in the $0^{\circ}$ plane (probably $\pm 0.1^{\circ}$ ) are given in Table 1.

Concerning the frequencies of these rods, it will be seen that the values given in columns 6 and 7 opposite the one whose length is oriented parallel to the direction $\gamma=+71.56^{\circ}$ differ by 0.97 per cent. This is in close agreement with the corresponding variation for the first rod given in the table, considering the (measured) direction along which the first rod is oriented.

Another rod was cut from a $30^{\circ}$ rectangular plate of the usual orientation. The results for this rod are shown in Table 1 , for $\gamma= \pm 90^{\circ}$. Inasmuch as Young's modulus passes through a minimum at this angle in the $30^{\circ}$ plane it was hoped that its value might thus be verified for the equatorial plane. Unfortunately the discrepancy turned out to be one of the largest.

It will be noted that with one exception all the "high frequency values" of Young's modulus are greater than the computed values. It appears quite possible that this excess, which is made more evident when lateral inertia effects are taken into account, may be in part a manifestation of elastic hysteresis. Experimenters studying mechanically excited vibrations of isotropic rods have uncovered such a discrepancy. However, the variations are all less than 2 per cent and three are within 1 per cent.

TABLE 1

\begin{tabular}{|c|c|c|c|c|c|c|c|c|c|c|}
\hline \multirow[b]{2}{*}{ Cut } & \multirow{2}{*}{$\begin{array}{l}\gamma \text { in de- } \\
\text { grees (as- } \\
\text { sumed) }\end{array}$} & \multicolumn{3}{|c|}{ Size } & \multirow{2}{*}{$\begin{array}{c}\text { Fre- } \\
\text { quency }\end{array}$} & \multirow{2}{*}{$\mid \begin{array}{l}4 \rho l^{2} f^{2} \\
\times 10^{-9}\end{array}$} & \multirow{2}{*}{$\begin{array}{l}4 \rho l^{2} f^{2} \\
\times k^{2 a} \\
\times 10^{-9}\end{array}$} & \multirow{2}{*}{$\begin{array}{c}\mathrm{E} \times 10^{-0} \\
(\text { theo- } \\
\text { retical })\end{array}$} & \multirow{2}{*}{$\begin{array}{c}\text { Depar- } \\
\text { ture }\end{array}$} & \multirow{2}{*}{$\begin{array}{l}\gamma \text { in degrees } \\
\text { (measured) }\end{array}$} \\
\hline & & $\begin{array}{c}\text { Thick- } \\
\text { ness }\end{array}$ & Breadth & Length & & & & & & \\
\hline 1 & 2 & & 3 & & 4 & 5 & 6 & 7 & 8 & 9 \\
\hline $0^{\circ}-$ & $\begin{array}{l}+71.60 \\
+10.83\end{array}$ & $\left\{\begin{array}{l}m m \\
4.81 \\
4.805 \\
4.81 \\
4.803\end{array}\right.$ & $\begin{array}{c}m m \\
18.27 \\
4.80 \\
22.70 \\
4.802\end{array}$ & $\begin{array}{c}m m \\
30.985 \\
30.985 \\
32.716 \\
32.716\end{array}$ & $\begin{array}{r}k c \\
82.4 \\
82.7 \\
95.4 \\
95.2\end{array}$ & $\begin{array}{r}692.00 \\
697.00 \\
1,035.00 \\
1,030.00\end{array}$ & $\begin{array}{r}707 \\
699 \\
1,037 \\
1,032\end{array}$ & $\begin{array}{r}691 \\
691 \\
1,014 \\
1,014\end{array}$ & $\left|\begin{array}{c}\text { Per cent } \\
\hdashline+1.16 \\
\hdashline+1.78\end{array}\right|$ & $\begin{array}{r}+71.95 \\
+71.95 \\
+10.68 \\
+10.68\end{array}$ \\
\hline $\begin{array}{l}0^{\circ}-. \\
30^{\circ} \text {. }\end{array}$ & $\begin{array}{l}-48.25 \\
\pm 29.1\end{array}$ & $\left\{\begin{array}{l}4.84 \\
4.813 \\
4.84 \\
4.836\end{array}\right.$ & $\begin{array}{c}20.62 \\
4.813 \\
31.28 \\
4.836\end{array}$ & $\begin{array}{l}28.92 \\
28.92 \\
45.165 \\
45.165\end{array}$ & $\begin{array}{r}120.9 \\
119.7 \\
69.7 \\
69.6\end{array}$ & $\begin{array}{l}1,298.00 \\
1,274.00 \\
1,051.00 \\
1,049.00\end{array}$ & $\begin{array}{l}1,304 \\
1,279 \\
1,055 \\
1,050\end{array}$ & $\begin{array}{l}1,285 \\
1,285 \\
1,045 \\
1,045\end{array}$ & $\begin{array}{c}-.47 \\
+.48\end{array}$ & $\begin{array}{l}-48.95 \\
-48.95 \\
\pm 28.47 \\
\pm 28.47\end{array}$ \\
\hline $\begin{array}{l}30^{\circ} \text {. } \\
0^{\circ} .\end{array}$ & \pm 90.0 & $\left\{\begin{array}{l}4.81 \\
4.805 \\
4.806 \\
4.806 \\
4.805\end{array}\right.$ & $\begin{array}{c}18.73 \\
4.827 \\
4.814 \\
4.826 \\
4.834\end{array}$ & $\begin{array}{l}34.517 \\
34.517 \\
32.409 \\
32.409 \\
32.409\end{array}$ & \begin{tabular}{|l|}
78.7 \\
78.7 \\
79.17 \\
79.007 \\
79.242
\end{tabular} & \begin{tabular}{r}
783.00 \\
783.00 \\
\hdashline 696.03 \\
-
\end{tabular} & $\begin{array}{l}797 \\
784 \\
697.7\end{array}$ & $\begin{array}{r}770 \\
770 \\
-691\end{array}$ & $\begin{array}{l}+1.82 \\
+.97\end{array}$ & $\begin{array}{c} \pm 90( \pm 0.02) \\
\pm 90( \pm 0.02) \\
+67.31 \\
+71.56 \\
+73.74\end{array}$ \\
\hline
\end{tabular}

ratio, and $l$ is the length.

(f) COMMENTS CONCERNING AIR CURRENT PATTERNS

An interesting fact, indicated first by the study of surface patterns and then well substantiated by studies of air current patterns, is that a quartz plate of a given cut will vibrate in much the same way regardless of its shape. The elastic properties appear to be the dominant factor in determining the type of vibration which a quartz plate will execute. Even in the case of the relatively long rod-like 
plate shown in Figure 15, the direction of the principal displacement is inclined toward the direction of the minimum Young's modulus. In the case of longer rods this tendency persists. This fact has an interesting bearing on the practice of clamping of $0^{\circ}$ rods. It has been demonstrated that the decrement of $0^{\circ}$ rods may be reduced by clamping at an angle indicated by the "nodal" line. It indicates also, of course, that improvement may be obtained by cutting the $0^{\circ}$ rod either parallel to the maximum or minimum Young's modulus. Rods are being prepared not in these directions, but oriented parallel to the direction $\gamma=-45^{\circ}$, in which Poisson's ratio for the $0^{\circ}$ plane (YZ-plane) is seen (in fig. 22) to be about zero. A rod cut in this direction is very nearly parallel to the direction of the maximum Young's modulus. Thirty-degree rods are being prepared also, parallel to $\gamma= \pm 45^{\circ}$, in which Poisson's ratio for the $30^{\circ}$ plane (XZ-plane) is practically zero. A rod cut in this direction is not very far from the direction of maximum Young's modulus for the $30^{\circ}$ plane, but as a matter of fact almost as far as an ordinary $0^{\circ}$ rod is from the minimum Young's modulus. Clamping experiments will be performed on these rods.

It was found in these studies of air currents that when plates of various cuts and shapes are caused to oscillate vigorously at one of their strong modes of high-frequency vibration, very pronounced air currents emanate from their uppermost major face. Although more difficult to produce, patterns of lycopodium powder blown from a major face give an excellent insight into the type and configuration of displacement of these higher frequency modes. To produce patterns of this nature the plate is caused to oscillate while in such a position that the major faces lie in vertical planes. A plane metallic surface may serve as one electrode. A screen was found quite convenient for the other. Obviously the wires forming the mesh should be spaced quite far apart, and should be strung only in a horizontal direction. Thus a heavy sheet of paper upon which a layer of lycopodium is sprinkled may be placed close to the major face behind the screen, in a position perpendicular to this face. If the process is carried out at various levels much information may be obtained concerning the displacement of this surface.

Studies of this nature have been carried on, but further work is required before results may be set forth with safety. Indisputable evidence has, however, been obtained through these initial studies that, as must be expected, the major surfaces break up into various antinodal areas at that relatively strong mode responding at the highest frequency, both for $0^{\circ}$ and $30^{\circ}$ plates. This precludes definitely the possibility of the frequency of response of a mode of this nature being any simple function of Young's modulus, in the direction of the thickness, and the thickness dimension. ${ }^{23}$

${ }^{23}$ As has already been pointed out, Crossley found evidence of this breaking up of the major faces. But notwithstanding this evidence, which he describes in the publication referred to in note 8 , he proceeds, as reported in this publication, to measure quantitatively Young's modulus by means of measurements of the thickness of the plate and the frequency of vibration, which values he substitutes in the equation he gives for Young's modulus, namely, $E=V^{2} D$, in which $D$ is the density, and $V=2 T F, F$ being the frequency and $T$ the thickness. In so doing he presupposes a half wave length distribution; in fact, he makes the statement: "The thickness of the crystal as previously stated is equal to one-half wave length of sound in quartz for the X-axis oscillation." This is undoubtedly a fallacious conception of the type and configuration of displacement obtaining. As may be expected, therefore, the value of Young's modulus as derived by him does not closely agree with the computed value corresponding to the direction parallel to the thickness dimension of a $0^{\circ}$ plate, which computed value has been checked within 2 per cent by the conventional method. Such a conception appears to lead him and others to consider Young's modulus as a constant of the type or mode of vibration rather than a constant of the material itself. 


\section{EXPERIMENTS OF A MORE SPECIFIC NATURE}

\section{STUDY OF THE AIR CURRENTS EMANATING FROM THE PERIPHERY OF CIRCULAR $0^{\circ}$ PLATES}

With the view in mind of determining with greater accuracy the angles of maximum radial displacement for the first and second modes of vibration of a $0^{\circ}$ cut circular plate, apparatus illustrated in Figure $16(a)$ and $(b)$ and Figure 17 was set up. The annular scale, $A$, in Figure $16(a)$ and $(b)$, graduated in thirds of a degree, is fixed to a heavy insulating base. Riding on a tapered shaft concentric with the annular scale, $A$, is the rotating member, $B$, in Figure $16(b)$, with arms, $B^{\prime}$ and $B^{\prime \prime}$, serving as verniers with which the angular position may be read to within one minute of arc. The revolving member, $B$, is also fitted with an insulated arm, $H$, by which it may be rotated. A cap, $C$, rests on top of the member $B$ serving as the final support for the quartz plate, $P$. At the center of the supporting cap, $C$, is a small circular face raised $0.2 \mathrm{~mm}$, upon which the quartz plate, $P$, rests, fixed in position with collodion. Above the quartz plate is the upper electrode $E$, supported on an adjustable arm, $F$. The supporting members, $C, B$, and $A$, below the quartz plate serve as the second electrode.

Suspended separately from the rest, on an adjustable supporting arm, $G$, hangs a celluloid vane, $V$, which is in length, measured horizontally, about equal to the diameter of the quartz plate, and in width, measured vertically, about equal to the thickness of the quartz plate. In other words, the effective area of the vane, $V$, is about equal to the projected area of the plate. The vane itself is about one-sixteenth inch thick. It is suspended on a fine tungsten wire which is held by a clamping device, $K$, designed to allow rotation. Centrally fixed to the vane, $V$, is a small mirror, $M$.

Referring now to Figure 17, a condensing lens, $L$, is so interposed between a light source, $L^{\prime}$, which is some 6 feet distant from the mirror, $M$, attached to the vane, $V$, that a sharp image of the vertical filament appears on a screen, $S$, placed about 15 feet from the mirror, $M$.

Means are provided for determining the angular position the member $B$ must take in order that the diameter passing through the centers of the verniers, $B^{\prime}$ and $B^{\prime \prime}$, on its arms shall pass through the center of the vane, $V$, as well as for holding the vane accurately perpendicular to that radius passing through its center.

When the vane is thus centered by rotation of the member $B$, whose angular position is noted, it is held by the means provided, accurately perpendicular until the light source, $L^{\prime}$, or the screen, $S$, may be so adjusted that the image of the filament is centered on the screen. The vane is then allowed to hang freely, and is rotated until the filament image is centered on the screen. The quartz plate is then set in oscillation by a single tube (UX210) circuit without regeneration. And the member $B$, is rotated until the filament image again returns to the center of the screen. The angular position of the member $B$ is again noted. Of course, steps must be taken to determine, in the case of the first mode of vibration of $0^{\circ}$ plates, which of the antinodes is being measured. With the size of vane used measurements of the antinodes of lesser amplitude did not prove practicable. 


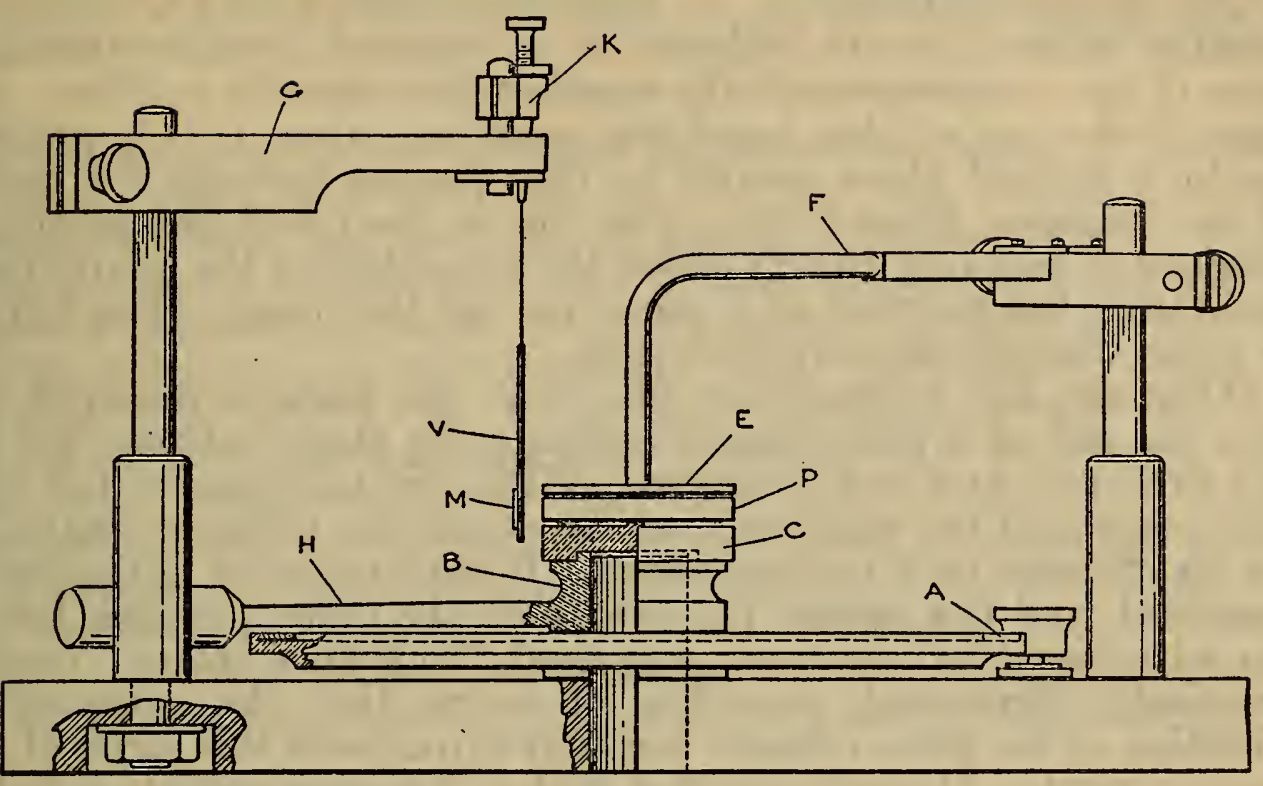

(a)

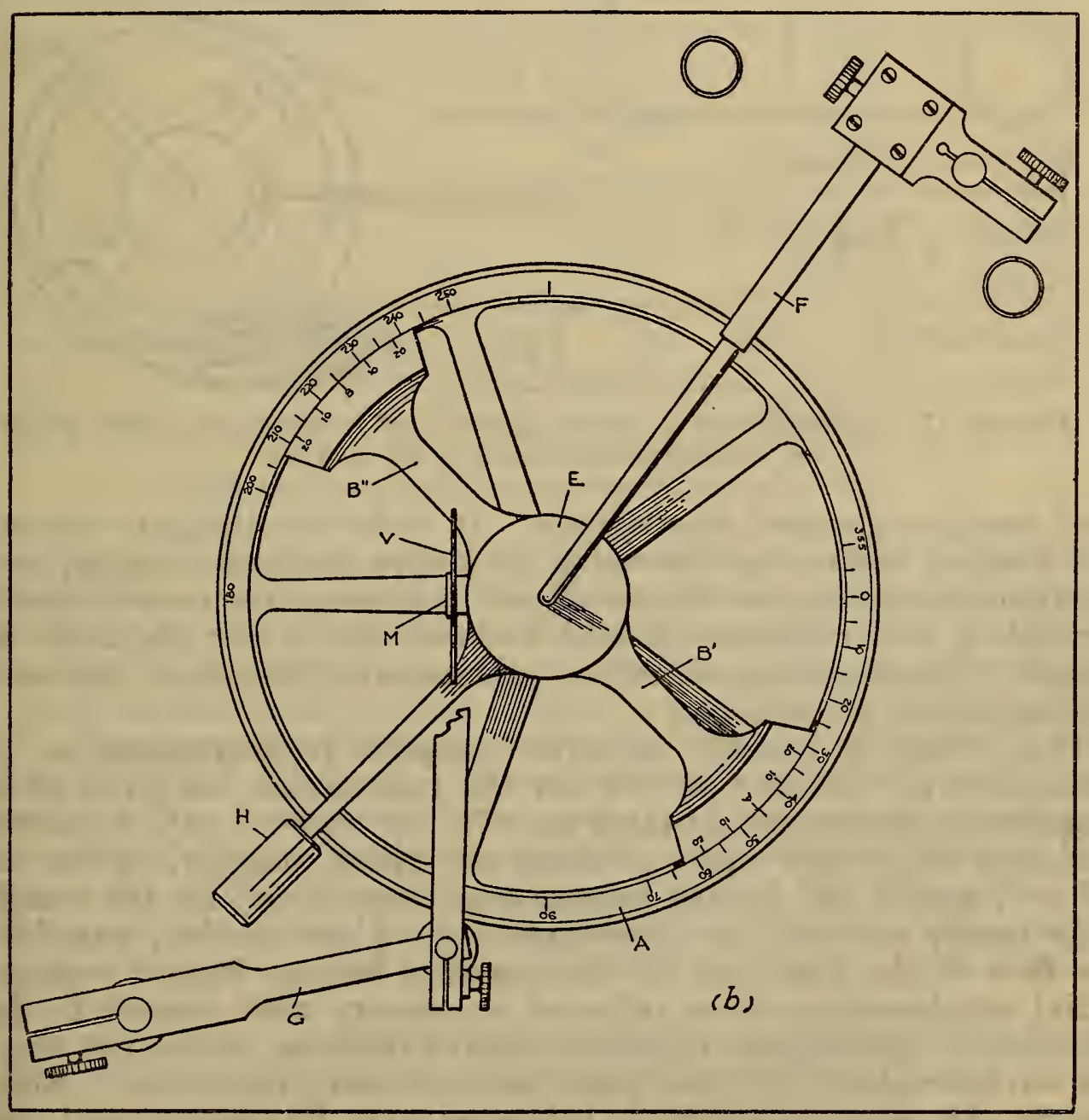

FIGURE 16.-Device for angular measurements of air currents emanating from periphery of circular plate

(a), elevation; (b), plan view. 
The upper electrode, $E$, is then swung clear, and a bench-like member whose legs are designed to be screwed down to the upper faces of the vernier arms of the member $B$, is fixed in position. One edge of the top of this bench-like member, when it is in position, lies in a vertical plane parallel to that passing through the centers of the verniers, $B^{\prime}$ and $B^{\prime \prime}$. The top of the bench-like member is designed to rest very closely above the upper face of the quartz plate, facilitating the drawing of a pencil line on the quartz plate parallel to a line through the vernier centers.

When the line is drawn on the plate, the plate is removed, and with the aid of a polarizing microscope the angle between the line and the optic axis is determined. With this information the angle with respect to the optic axis, of the maximum pressure created by the air currents may be determined. If both principal antinodes are measured, and the process repeated with the plate inverted, leaving the adjustment of the vane unaltered, "machine errors" may be practically eliminated, providing of course that the amplitude of vibration of the plate remains constant throughout this series of four measurements. It was found that with a change in amplitude indivi-

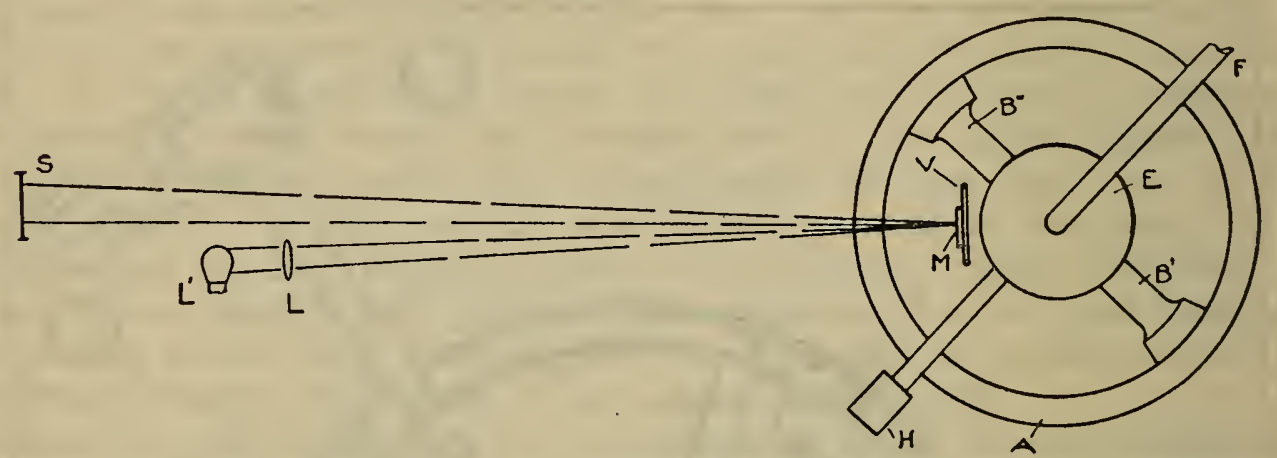

FIGURE 17.-Arrangement of optical system used in conjunction with device for angular measurement of air currents

dual readings changed appreciably. In order to eliminate errors of this nature, means was provided to insure constant air-gap, and a vacuum tube voltmeter was employed to measure the current flowing through a low resistance placed between the lower electrode and ground. These arrangements proved adequate; with them, individual readings could be repeated.

The results of a series of seven complete measurements on one plate gave $73^{\circ} 30^{\prime}$ and $48^{\circ} 24^{\prime}$ for the two modes. A series of five measurements on a second plate gave $73^{\circ} 28^{\prime}$ and $48^{\circ} 44^{\prime}$. Maximum deviation from the average of these two plates, namely, $73^{\circ} 29^{\prime}$ and $48^{\circ} 34^{\prime}$, was $0^{\circ} 29^{\prime}$ for the greater angle and $0^{\circ} 38^{\prime}$ for the smaller.

As nearly as could be determined, any plane section, parallel to the face of the plate, of the air currents issuing from a region of radial displacement show refiected symmetry with respect to their maximum. Indications of slight relative rotation, about the axis of the circular plate, of these plane sections were uncovered. Effects due to this possible rotation, however, were "averaged out" with the "machine errors." Thus it appears that these measurements should represent quite accurately the angle of maximum radial displacement. 
2. STUDIES OF THE DISPLACEMENT OF THE PERIPHERY OF ZERODEGREE CIRCULAR PLATES BY MEANS OF A PROBING MECHANISM

(a) FIRST MODE OF A $0^{\circ}$ CIRCULAR PLATE

In the study of powder patterns formed on the face of $0^{\circ}$ circular plates, a "nodal" line was found at $-17^{\circ} 30^{\prime}\left( \pm 1^{\circ}\right)$ from the optic axis in the case of the first mode of vibration, indicating that, if the pattern of radial displacement were to show reflected symmetry with respect to a plane perpendicular to the face of the plate and passing through the maximum, this maximum radial displacement would be found at $+72^{\circ} 30^{\prime}\left( \pm 1^{\circ}\right)$. In the study, in which a vane was utilized, of air currents emanating from the same plate vibrating at the same mode, results indicated that this angle of maximum radial displacement would be found at $+73^{\circ} 29^{\prime}\left( \pm 29^{\prime}\right)$. Although agreement between the two is evident, the measurements in both cases are only indirectly representative, and not in themselves entirely trustworthy. Further correlation was needed. Other means of measuring this angle were sought for and found in the device to be described.

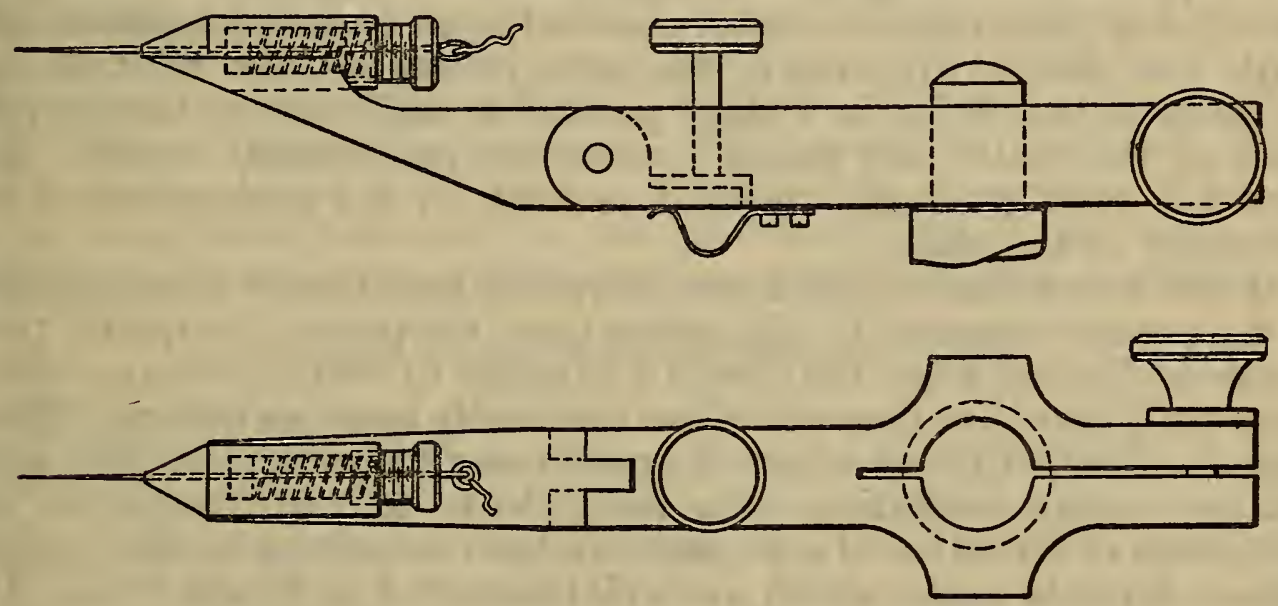

Figure 18.-Device for probing surface of plates

In Figure 18 is given a drawing to illustrate the general character of this device. It will be seen that it consists of a very sturdy adjustable arm in the end of which is a cylindrical chamber which constrains the motion of a piston fitting snuggly within. Affixed to the piston is a steel needle which projects through a small hole in the end of the arm. Bearing on the piston is a coil spring, tending to force the needle outward through this hole. The other or eye end of the needle projects through a small hole in the center of a plug which screws into the open end of the cylindrical chamber. By virtue of the fact that the rear end of the spring rests against this plug, the pressure on the piston may be adjusted by screwing the plug in or out. The needle may be withdrawn against this pressure by means of a wire attached to the eye in its end.

The plate to be studied by probing is placed on a cap similar to $C$ in Figure $16(a)$ which for this purpose is rigidly attached to the revolving member $B$, shown in the same figure, to insure against relative rotation of the two. In the center of the upper face of this cap is a small raised surface, as before, upon which the quartz plate rests. The cap used in this instance, however, differs from the one used previously in that it embodies two arms. The purpose of these 
arms is to allow clamping of the quartz plate, which is obviously necessary if probing operations, with a device such as described, are to succeed. Another cap with corresponding arms is rigidly supported above the one fixed to the member $B$. The means of support consists simply of suitable spacers placed between the arms, which are flat bars, one running across above the upper cap and one running below the lower; with bolts drawing the two bars or arms together. Adequate electrical insulation between the two caps, of course, is provided so that each may serve as an electrode. A screw through the center of the upper cap bears down on the center of the upper face of the quartz plate, pressing the plate down on the small raised surface in the center of the lower cap, thus rigidly clamping the plate. ${ }^{24}$ It was found that the plate can be clamped in this manner with sufficient force to prevent it from moving when being probed, without interfering seriously with its oscillation at several modes of lowfrequency response.

The probing device is firmly mounted within range of the periphery of the plate thus clamped. The plate is set in oscillation, using the same tuned-plate piezo oscillator used in the air current measurements. With the needle withdrawn, the arm is swung into position and adjusted so that it lies in a plane parallel to and midway between the faces of the plate, and points toward the geometrical center. The needle is then gradually released to bear on the midportion of the periphery of the plate.

It was found that within a certain rather broad range of adjustment of the pressure exerted by the spring upon the piston, the quartz plate ceases oscillation when the needle is brought to bear on certain regions of its periphery, but does not when the needle bears on others. Those regions of its periphery where the needle can be brought to bear without preventing oscillation, were found to be four in number for the first mode of virbation of a $0^{\circ}$ plate, and to correspond to the "nodal" regions for this mode, which are well illustrated in Figure $9, A$. The centers of these "nodal" regions are nodes of radial displacement, but not necessarily points at which displacements of all types vanish.

According to the procedure finally adopted, one of the "nodal" regions is sought out by continued trial, care being taken that the needle is withdrawn each time before the member $B$ is rotated, in order to avoid rotation of the plate in the mounting. When one of these regions is located it is probed in minute successive steps, working outward from the center until the point is reached at which the quartz plate first falls out of oscillation. The angular position of the member $B$ at this point is recorded. The same "nodal" region is then probed from the center outward in the opposite direction until a second similar point is found, at which the position of the member $B$ is again recorded.

The four "nodal" regions are probed numerous times, for individual readings vary as much as $2^{\circ}$ or $3^{\circ}$, on the average. The needle is then released to bear on the plate at some point for which the angular position of the member $B$ is recorded, and by means of the adjusting screw it is raised vertically while still bearing on the plate, thus marking the periphery of the plate with a very fine line perpendicular to the faces. This process is repeated for the position of the plate

\footnotetext{
24 Doctor Hund, while working at the National Bureau of Standards, built a plate holder incorporating this principle of rigid mounting.
} 
represented by a rotation of member $B$ through $180^{\circ}$. These marks are run to the upper face of the plate so that with a straight-edge and a magnifying glass a line may be drawn between them on the face of the plate without the introduction of any appreciable error. With the determination of the angle between the line and the optic axis, which is readily accomplished with a polarizing microscope, the measurement is completely determined.

Six series of such measurements were performed at the first mode. The average of the six series places the "nodes" at $+20^{\circ} 4^{\prime},+126^{\circ}$ $54^{\prime},-53^{\circ} 6^{\prime}$, and $-159^{\circ} 56^{\prime}$ from the optic axis. The "nodes" referred to are, of course, the points midway between the pairs of points at which the plate first falls out of oscillation. Assuming reflected symmetry of the amplitude of displacement with respect to the maximum amplitude, the maximum of one of the principal antinodes would fall at $+73^{\circ} 29^{\prime}$. This is exactly the value obtained through measurement of air currents. The fact that the air-current measurements were somewhat more closely related to the maximum displacement than to the minimum, while the probing results are more closely related to the "nodal" regions, which measured on the average with the particular spring used some $8^{\circ}$ to $10^{\circ}$ in extent, rather than to the antinodal ones, indicates reflected symmetry of amplitude of radial displacement. The maximum deviation from the above average of $+73^{\circ} 29^{\prime}$ was $0^{\circ} 28^{\prime}$ for the six series. Three of the six series were performed on one plate and three on another. No difference between the two plates was detected in these measurements.

\section{(b) SECOND MODE OF A $0^{\circ}$ CIRCULAR PLATE}

A similar probing study was made of the second mode of $0^{\circ}$ circular plates. Seven series, each consisting of a number of individual readings, averaged $+44^{\circ} 26^{\prime}\left( \pm 48^{\prime}\right)$ for a line joining the two "nodal" points, indicating that if the displacement were to show reflected symmetry with respect to the maximum, the maximum displacement would take place at $-45^{\circ} 34^{\prime}\left( \pm 48^{\prime}\right)$. The "nodal" points referred to here as before are the points midway between the pairs of points at which the plate first ceases oscillation. This angle does not agree closely with results obtained through angular measurement of the air currents, namely, $-48^{\circ} 34^{\prime}\left( \pm 38^{\prime}\right)$. Here we have indication of dissymmetry of radial displacement, made particularly evident, if the measurements are to be trusted, by the fact that the "nodal" regions as measured in this manner averaged in this case approximately $80^{\circ}$ in extent, with the particular spring pressure used. Further indication may be found in Figure $9, B$, in which the pattern formed by the air currents indicates that the maximum radial displacement is to be found farther from the optic axis than would be the perpendicular bisector of the "nodal" line. Four of the seven series were performed on one plate and three on another. As before, no difference between the two plates was evident.

(c) THE MODE OF A 36.03 BY 4.805 MM 0 CIRCULAR PLATE RESPONDING AT $136 \mathrm{KC}$

A third probing study was made on the $136 \mathrm{kc}$ mode of oscillation of a 36.03 by $4.805 \mathrm{~mm} 0^{\circ}$ circular plate. Only one series of measurements was carried out. It indicated the presence of a "nodal" point of radial displacement at $+13^{\circ} 14^{\prime}$ and another at $-82^{\circ} 29^{\prime}$, 
the former being somewhat strictly nodal in nature, while the latter appears to be perhaps an antinode of tangential displacement. The surface powder pattern for this mode is given in Figure $3, F$.

\section{(d) COMMENTS CONCERNING RESULTS OF PROBING STUDIES}

The probing operations not only proved successful in themselves as means of studying the oscillations of plates, but, in addition, they help to substantiate the results obtained in the studies of air currents emanating from the plate, in which a vane was utilized. The exact agreement between the results of the two methods of measurement in the case of the first mode of vibration is fairly good reason to believe that this maximum does take place at $+73^{\circ} 29^{\prime}\left( \pm 29^{\prime}\right)$ and that the amplitude of radial displacement closely approaches reflected symmetry with respect to its maximum.

This agreement in the case of the first mode is also a reason for accepting with some confidence the results of the two methods of measurement obtained for the second mode of vibration, which indicate dissymmetry of the amplitude of radial displacement, and a maximum at $-48^{\circ} 34^{\prime}\left( \pm 38^{\circ}\right)$.

Although they have not been thus applied, it is believed that probing methods may be profitably employed as a means of studying the third mode of $0^{\circ}$ plates.

\section{COMIMENT AND CONCLUSION}

Many conclusions may be drawn quite readily from the results of the various methods of study of the vibrations of quartz plates described above. First of all it is increasingly evident that the production and observation of luminous discharge phenomena constitute a relatively poor method of studying these modes of vibration. Certainly no reasons were discovered showing necessity or even desirability of reversion to that method of attack. Another conculsion to be drawn is that there are at our command several quite direct methods for studying modes of vibration of quartz plates which may be employed with greater ease than the optical method involving the production of figures caused by interference of light waves. This optical method, moreover, it not as readily adapted to the study of different modes of vibration.

A third conculsion of a general nature to which attention was called in a preceding section, is that the magnitude and direction of critical values of Young's modulus play an exceedingly important rôle in the determination of the nature of various modes of vibration of plates of an anistropic material.

Turning now to the more specific aspects of these various studies, it is to be concluded that the magnitude of all computed critical values of Young's modulus in the $0^{\circ}$ plane, and the maximum value and that one of the two minima which is to be found perpendicular to the optic axis, in the $30^{\circ}$ plane, have been experimentally verified within 2 per cent.

In addition to these verifications in magnitude, the direction of one of the critical values of Young's modulus has been verified within about a degree. This critical value is the maximum. The fact that the magnitudes of all critical values except that in the direction of the optic axis (for the $30^{\circ}$ plane) have been quite closely verified, 
and that one has been verified as to its direction, should be considered as very good reason for accepting the other predicted directions of critical values as accurate within close limits. In other words, it is to be concluded that from the various measurements and observations, the equation for Young's modulus as originally derived and evaluated by Voigt ${ }^{25}$ has been found to be quite accurate in all respects.

In general, a large amount of information was gained concerning the oscillation of rods ${ }^{26}$ and plates. The relating of the frequencies of the three modes of strongest response of a rectangular plate to its three dimensions is shown to be prompted by misconceptions. ${ }^{27}$ Of particular interest were the more specialized studies of the first and second modes of $0^{\circ}$ circular plates. These two cases presented convenient sources of detailed information concerning the oscillation of quartz plates. Just why a $0^{\circ}$ circular plate oscillates as it does at these two frequencies, to say nothing of other frequencies or other plates, is yet to be learned, of course. ${ }^{28}$ But facts have been uncovered which have important bearing on the subject. For instance, the fact that Poisson's ratio for the $0^{\circ}$ plane is very small in the directions $\gamma=$ $\pm 45^{\circ}$, whereas its value in the vicinity of $\gamma=-16^{\circ}$ is relatively large, is good reason why the two modes may be expected to differ. Furthermore, in view of knowledge concerning these two modes gained experimentally, it must be considered as somewhat of a coincidence that the two frequencies bear the relation of approximately $1: \sqrt{2}$ despite the fact that the values of Young's modulus in the direction of the maximum radial displacement for the two cases are to each other quite closely as $2: 1$.

In the course of the various experiments seven $0^{\circ}$ circular plates were broken during oscillation. Without exception the cleavage planes were found to be roughly perdendicular to the faces of the plate. Whenever a plate cracked in such a manner that two cleavage planes were not parallel, it was found that these planes always intersected the face of the plate at about equal angles from the optic axis, on the average \pm 38.1 . Three of these plates cracked into but two pieces with a fairly smooth uniform cleavage plane through a diameter, or nearly so, in each case. Unfortunately two of these plates included considerable twinning. As nearly as could be determined, however, all parted at planes intersecting the face of the plate in a direction for which, roughly, $\gamma=+38.1^{\circ}$. Reasons for these phenomena are not apparent.

As a result of information gained and intimations found in the various studies carried on, experiments are now being performed on the various means of mounting plates and rods which have suggested themselves. Although it is not clear at this point how present general practice may be much improved upon, certain possibilities of improvement in methods of mounting plates and rods which are to be used as standards of frequency, have presented themselves. The experi-

${ }^{25} \mathrm{~W}$. Voigt, Bestimmung der Elasticitatsconstanten von Beryll und Bergkrystall, Ann. der Phys., 31, pp. 474-501 and 701-724; 1889 .

${ }_{26}$ Our observations explain very well, for instance, the reason for the variation in intensity, over the end of a $0^{\circ}$ rod noticed and reported by E. P. Tawil, Les Ondes Stationnaires Ultra-Sonores Rendues Visibles dans les Gaz par la Méthode des Stries, Compt. Rend. 191, pp. 92-95; 1930; of the supersonic waves emanating therefrom.

${ }_{27}$ Results of these various studies anwer in a rery definite manner many questions such as those brought up by P. T. Kao, Sur les Vibrations du Quartz Piézoélectrique Suivant l'Axe Optique, Compt. Rẹnd. 191, pp. 768-770; 1930. 
ments on the clamping of rods has already been mentioned. The possibilities offered through the clamping of circular plates at the center, both $0^{\circ}$ and $30^{\circ}$, look quite promising. One very interesting method of accomplishing this end involves the drilling of a small hole in the center of each face of the plate to a depth of nearly one-half its thickness. The plate may then be rigidly held by means of two rods fixed to the electrodes. This method, among others, is being tried at present.

The authors wish to acknowledge the inestimable assistance in these studies given them by J. E. Williard, who with the greatest of care cut and ground all the plates and rods with great accuracy, and by $\mathrm{E}$. F. Webb, under whose very capable direction the cutting and grinding was done.

\section{SUPPLEMENTARY NOTE}

A. Meissner has attempted to relate the preferred angle of radial displacement; that is, the angle of maximum radial displacement, at the two lower modes of response of $0^{\circ}$ circular plates, to certain directions determined by the silicon atoms in the lattice structure of quartz, by assuming that the smaller one of the two angles, namely, the angle of maximum radial displacement during oscillation at the second mode, corresponds to that direction in the planes of greatest "atomic density" parallel to the intersection of these planes with the YZ-plane or $0^{\circ}$ plane. By "atomic density" he apparently means the number of atoms in a given plane per unit area, times the atomic weight. He tacitly assumes that the other favored angle of radial displacement; that is, the angle of maixmum displacement in the case of first mode, corresponds to that direction determined by the intersection with the $0^{\circ}$ plane of planes which have a very low value of this "atomic density." It is rather difficult to conceive how this low value of "atomic density" would bring about angular stability of oscillation.

However this may be, he proceeds to explain, referring to that element of the silicon atom lattice structure which, according to some indications (see Sosman, Properties of Silica), somewhat closely resembles a cube, one of whose diagonalis lies parallel to the principal crystallographic axis, that if that diagonal of the rhombohedron parallel to the optic or principal axis is sufficiently reduced in dimension relative to the interatomic distances, which are left undisturbed, measured in planes perpendicular to the optic axis, planes of maximum "atomic density" will be inclined about $-37^{\circ}$ with respect to the optic axis. The "complementary" angle would be in this case about $+58^{\circ}$. This is the angle at which planes which pass through approximately $1 / \sqrt{2}$ as many silicon atoms as do the planes of maximum "atomic density" intersect the $Y Z$ or $0^{\circ}$ plane. He found that the smaller one of these two angles corresponded well with the lowest values of the angles of maximum radial displacement for the two modes of oscillation, measured by various means experimentally, and reported by him variously as $+71^{\circ}\left( \pm 2^{\circ}\right)$ and $-48^{\circ}\left( \pm 2^{\circ}\right)$ in the publication referred to in note 5 ; as about $-46^{\circ}$ in the publication referred to in note 17 ; and as $-44^{\circ},-39^{\circ},-37^{\circ}$, or $-34.5^{\circ}$ in the publication referred to in note 7 . He lightly passes over the large discrepancy between the larger of these two angles and the measured angle of $+71^{\circ}\left( \pm 2^{\circ}\right)$, whereas this angular measurement and the corresponding measurement for the other mode, namely $-48^{\circ}\left( \pm 2^{\circ}\right)$, which were the first reported, agree nicely with those described here. Therefore, if the angles at which these planes intersect the $0^{\circ}$ plane are to correspond to the angles of maximum radial displacement for the two modes of oscillation, the length of the diagonal of the rhombohedron parallel to the optic axis must be still further reduced relative to interatomic distances in planes perpendicular thereto. As a matter of fact, the diagonal would have to be reduced to a value less than the interatomic distance in these planes perpendicular to the optic axis, a condition widely different from what is indicated by $\mathrm{X}$-ray and other measurements.

What would appear a more logical attempt, with the purpose in mind of gaining information concerning the ratio $\frac{a}{c}$ would be that to disclose relations which obviously must exist between the well-established elastic characteristics of quartz and the lattice structure. If the dependence of the elastic and piezo-electric 
characteristics upon the lattice structure could be entirely disclosed the lattice structure would obviously be determined.

Considering again the rhombohedron, we find indicated dissymmetry in the zero plane (parallel to the diagonal plane cutting two edges and four diagonally opposite corners, and, therefore, including two diagnoals, one of which is that one parallel to the optic axis), and reflected symmetry in the $30^{\circ}$ planes. We find that the equatorial plane has a simple relation, easily definable in terms of the atoms it intersects, to the lattice structure. The $0^{\circ}$ plane also is seen to be simply or critically related to the lattice structure. The $30^{\circ}$ plane is seen, moreover, not to be so critically related, particularly if the presence of two oxygen atoms in the near vicinity of each silicon atom is considered. We find planes of such critical nature making angles of some $30^{\circ}$ to $40^{\circ}$ and some $50^{\circ}$ to $60^{\circ}$ with respect to the optic axis, which planes include an $\mathrm{X}$ axis, or electric axis. All these critical planes, overlooking the discrepaney in the case of the last two, include directions of critical values of Young's modulus. All in all, we find indications of the intimate relationship which must exist. But discrepancies show that there are probably other factors which must be considered. One of these is no doubt the presence of two similar lattice structures of oxygen atoms. Explanations of why a plane, including the electric axis, which makes an angle of about $11^{\circ}$ with the optic axis includes a critical direction of Young's modulus; of why the value of this modulus is the same for all directions in the equatorial plane; and of why the angles at which the two critical planes intersect the YZ plane do not correspond to the angles of maximum and minimum Young's modulus, may all be found if the presence of the oxygen atoms is taken into account.

\section{Appendix I.-THE DEVELOPMENT OF POISSON'S RATIO AND THE MODULUS OF RIGIDITY FOR CRYSTALLINE QUARTZ}

When the experimental studies described above were first undertaken it became increasingly evident that the expression for Young's modulus of quartz as a function of direction was practically the only mathematical development available as an aid to the interpretation and understanding of the results. It was deemed very expedient, therefore, to develop and numerically evaluate like expressions for Poisson's ratio and the modulus of rigidity for quartz as functions of orientation.

In general form Love ${ }^{29}$ expresses Young's modulus, the modulus of rigidity, and Poisson's ratio in terms of the elastic moduli, respectively, as

and

$$
\begin{aligned}
& E=\frac{\Delta}{\phi} \\
& \mu=\frac{\Delta}{\phi^{\prime}}
\end{aligned}
$$

$$
\begin{gathered}
\text { and } \quad \phi=\left(S_{11}, S_{22}, \cdots S_{12}, \cdots\right)\left(l^{2}, m^{2}, n^{2}, m n, n l, l m\right)^{2} \\
\phi^{\prime}=\left(S_{11}, S_{22}, \cdots S_{12}, \cdots\right)\left(2 l l^{\prime}, 2 m m^{\prime}, 2 n n^{\prime}, m n^{\prime}+m^{\prime} n,\right. \\
n l^{\prime}+n^{\prime} l, l m^{\prime}+l^{\prime} \\
m)^{2}
\end{gathered}
$$

in which

$$
\begin{array}{r}
\sigma=-\frac{1}{2 \phi}\left[l^{\prime 2} \frac{\partial \phi}{\partial\left(l^{2}\right)}+m^{\prime 2} \frac{\partial \phi}{\partial\left(m^{2}\right)}+n^{\prime 2} \frac{\partial \phi}{\partial\left(n^{2}\right)}\right. \\
\left.+m^{\prime} n^{\prime} \frac{\partial \phi}{\partial(m n)}+n^{\prime} l^{\prime} \frac{\partial \phi}{\partial(n l)}+m^{\prime} l^{\prime} \frac{\partial \phi}{\partial(m l)}\right]
\end{array}
$$

${ }^{29}$ A Treatise on the Mathematical Theory of Elasticity.

68723-31-9 
In these expressions the terms $S_{r s}$ are the various minors ${ }^{30}$ of the determinant, $\Delta$, of the elastic constants, and $l, m, n$, and $l^{\prime}, m^{\prime}, n^{\prime}$ are direction cosines. In the expression for Young's modulus the direction $(l, m, n)$ is that of the related simple stress. In the expression for the rigidity the directions $(l, m, n)$ and $\left(l^{\prime}, m^{\prime}, n^{\prime}\right)$ correspond to the normals to the pair of orthogonal planes across which the related stress is considered. And in the expression for Poisson's ratio the direction $(l, m, n)$ is to be indentified with that of the principal stress and $\left(l^{\prime}, m^{\prime}, n^{\prime}\right)$ that of the accompanying lateral stress, or vice versa.

Voigt, ${ }^{31}$ through considerations of symmetry, determined the following relations among the elastic constants of quartz:

$$
\begin{array}{cc}
c_{22}=c_{11} & c_{55}=c_{44} \\
c_{23}=c_{13} & c_{56}=c_{14} \\
c_{24}=-c_{14} & c_{56}=\frac{c_{11}-c_{12}}{2}
\end{array}
$$

and

$$
c_{15}=c_{16}=c_{25}=c_{26}=c_{34}=c_{35}=c_{36}=c_{45}=c_{46}=0
$$

The orientation assumed by him in determining these relations involved the coincidence of the principal crystallographic axis with the $\mathrm{Z}$ axis, electric axis with the $\mathrm{X}$ axis, and "mechanical" axis with the $\mathrm{Y}$ axis, as illustrated in Figure 25.

The corresponding relations among minors is then:

and

$$
\begin{array}{ll}
S_{22}=S_{11} & S_{55}=S_{44} \\
S_{23}=S_{13} & S_{56}=2 S_{14} \\
S_{24}=-S_{14} & S_{66}=2\left(S_{11}-S_{12}\right)
\end{array}
$$

$$
S_{15}=S_{16}=S_{25}=S_{26}=S_{34}=S_{35}=S_{36}=S_{45}=S_{46}=0
$$

With these relations (7) the function $\phi$ given in (4) may be expanded in the form

$$
\begin{aligned}
& \phi= S_{11} l^{4}+S_{11} m^{4}+2 S_{11} l^{2} m^{2}+ \\
&+S_{33} n^{4}+\left(S_{44}+2 S_{13}\right)\left(S_{14} m n\left(3 l^{2}-m^{2}\right)\right. \\
&= S_{11}+\left(S_{11}+S_{33}-S_{44}-2 S_{13}\right) \cos ^{4} \gamma-\left(2 S_{11}-S_{44}-2 S_{13}\right) \cos ^{2} \gamma \\
&-2 S_{14} \sin ^{3} \gamma \cos \gamma \cos 3 C
\end{aligned}
$$

where $\gamma$ represents the angle measured from the optic axis ( $Z$ axis), and $C$, the "angle of cut," is measured from a mechanical axis ( $Y$ axis), as shown diagrammatically in Figure 19. This in turn may be written

where

$$
\begin{gathered}
\phi=\Delta\left[s_{11}+\left(s_{11}+s_{33}-s_{44}-2 s_{13}\right) \cos ^{4} \gamma-\left(2 s_{11}-s_{44}-2 s_{13}\right) \cos ^{2} \gamma\right. \\
\left.-2 s_{14} \sin ^{3} \gamma \cos \gamma \cos 3 C\right]
\end{gathered}
$$

Then from (1)

$$
s_{r s}=S_{r s} / \Delta
$$

$$
\begin{gathered}
\frac{1}{E}=s_{11}+\left(s_{11}+s_{33}-s_{44}-2 s_{13}\right) \cos ^{4} \gamma-\left(2 s_{11}-s_{44}-2 s_{13}\right) \cos ^{2} \gamma \\
-2 s_{14} \sin ^{3} \gamma \cos \gamma \cos 3 C
\end{gathered}
$$

${ }_{30}$ The quantitics $1 / 2 S_{18} / \Delta, \ldots S_{12} / \Delta, \ldots$ are the coeflicients of the strain-energyfunction, which is in this case a function of the stress components. The quantities $S_{11} / \Delta, \ldots 2 S_{12} / \Delta, \ldots$ are termed by Voigt the elastic moduli, and denoted by him $S_{r}$.

s1 See footnote 25, p. 543. 
In a similar manner, from (5)

$$
\begin{aligned}
& \phi^{\prime}= 4 S_{11}\left(l^{2} l^{\prime 2}+m^{2} m^{\prime 2}\right)+2 S_{11}\left(l m^{\prime}+l^{\prime} m\right)^{2}-2 S_{12}\left(l m^{\prime}-l^{\prime} m\right)^{2} \\
&+8 S_{13} n n^{\prime}\left(l l^{\prime}+m m^{\prime}\right)+4 S_{33} n^{2} n^{\prime 2} \\
&+S_{44}\left[\left(m n^{\prime}+m^{\prime} n\right)^{2}+\left(n l^{\prime}+n^{\prime} l\right)^{2}\right] \\
&+4 S_{14}\left[l l^{\prime}\left(m n^{\prime}+m^{\prime} n\right)-m m^{\prime}\left(m n^{\prime}+m^{\prime} n\right)+\left(n l^{\prime}+n^{\prime} l\right)\left(l m^{\prime}+l^{\prime} m\right)\right] \\
&=\Delta\left\{s_{44}+\left(s_{11}+s_{33}-s_{44}-2 s_{13}\right) \cos ^{2} B \sin ^{2} 2 \gamma+\left(2 s_{11}-s_{14}\right.\right. \\
&\left.-2 s_{12}\right) \sin ^{2} B \sin ^{2} \gamma+s_{14}\left[-\cos ^{2} B \sin 4 \gamma \cos 3 C\right.
\end{aligned}
$$

$\left.\left.+2 \sin ^{2} B \sin 2 \gamma \cos 3 C+2 \sin 2 B \sin \gamma\left(2 \cos ^{2} \gamma-\sin ^{2} \gamma\right) \sin 3 C\right]\right\}$

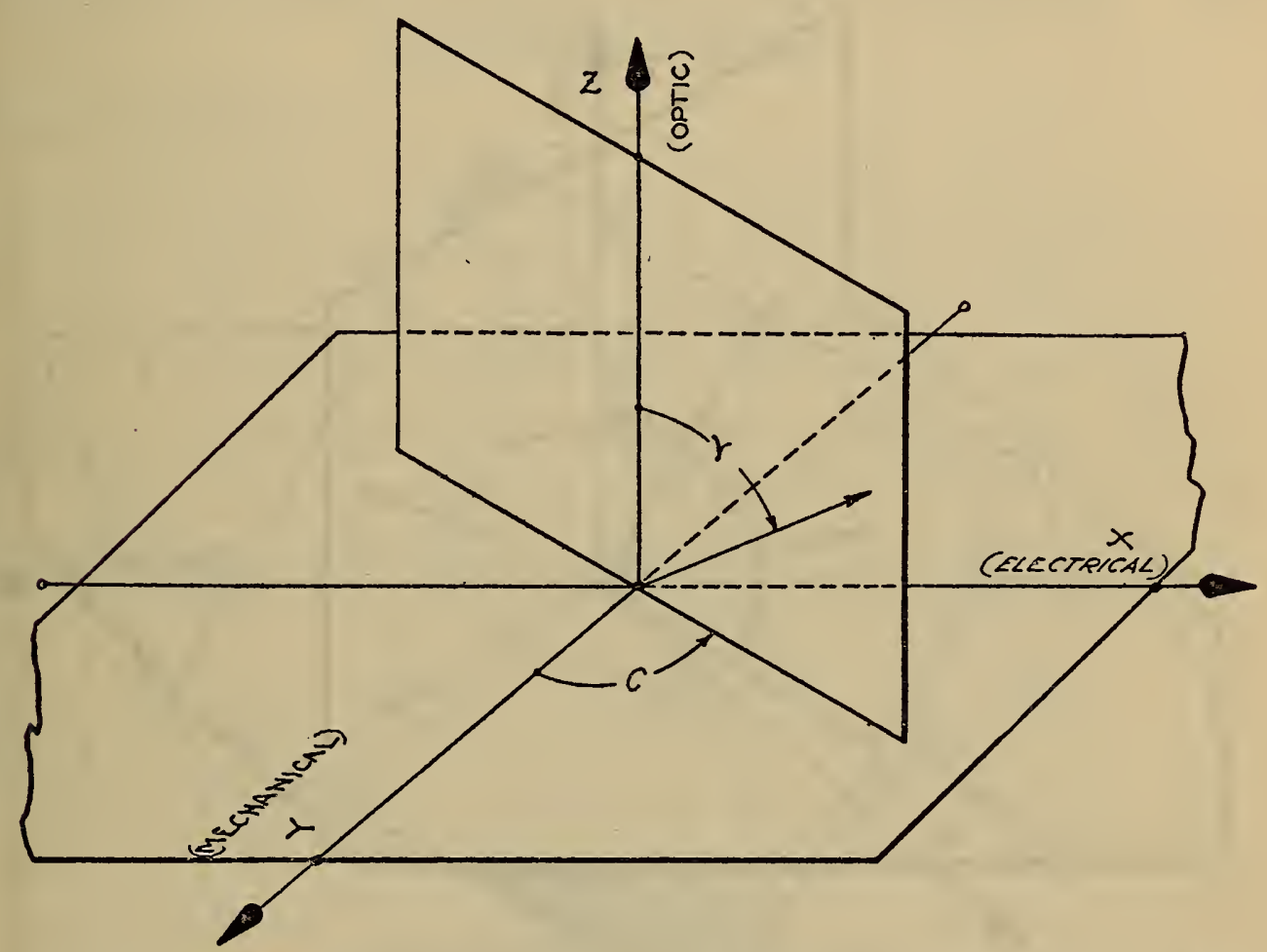

FIGURE 19.-Diagrammatic illustration of the angles represented by $\gamma$ and $C$.

In this expression the angle $B$ is that illustrated in Figure 20.

From (2) then

$$
\begin{gathered}
\frac{1}{\mu}=s_{44}+\left(s_{11}+s_{33}-2 s_{13}\right) \cos ^{2} B \sin ^{2} 2 \gamma+\left(2 s_{11}-s_{44}-2 s_{12}\right) \sin ^{2} B \sin ^{2} \gamma \\
+s_{14}\left[-\cos ^{2} B \sin 4 \gamma \cos 3 C+2 \sin ^{2} B \sin 2 \gamma \cos 3 C\right. \\
\left.+2 \sin 2 B \sin \gamma\left(2 \cos ^{2} \gamma-\sin ^{2} \gamma\right) \sin 3 C\right]
\end{gathered}
$$

Having expanded the function $\phi$, we proceed with the expansion of the expression for Poisson's ratio, (3)

$$
\begin{aligned}
\sigma= & -\frac{1}{\phi}\left\{S_{11}\left(l l^{\prime}+m m^{\prime}\right)^{2}+S_{12}\left(m l^{\prime}-l m^{\prime}\right)^{2}+s_{13}\left[n^{2}\left(l^{\prime 2}+m^{\prime 2}\right)\right.\right. \\
& \left.+n^{\prime 2}\left(l^{2}+m^{2}\right)\right]+S_{14}\left[m n\left(l^{\prime 2}-m^{\prime 2}\right)+m^{\prime} n^{\prime}\left(l^{2}-m^{2}\right)\right. \\
& \left.\left.+2 l l^{\prime}\left(m n^{\prime}+m^{\prime} n\right)\right]+S_{33} n^{2} n^{\prime 2}+S_{44} n n^{\prime}\left(m m^{\prime}+l l^{\prime}\right)\right\}
\end{aligned}
$$


Using the relation $s_{r s}=S_{r s} / \Delta$, this becomes $\begin{aligned} \sigma & =-\left\{s_{13}+\frac{1}{4}\left(s_{11}+s_{33}-s_{44}-2 s_{13}\right) \cos ^{2} B \sin ^{2} 2 \gamma+\left(s_{12}-s_{13}\right) \sin ^{2} B \sin ^{2} \gamma\right. \\ & +\frac{1}{4} s_{14}\left[-\cos ^{2} B \sin 4 \gamma \cos 3 C+2 \sin ^{2} B \sin 2 \gamma \cdot \cos 3 C+2 \sin 2 B \sin \gamma\right.\end{aligned}$ $\left.\left.\left(2 \cos ^{2} \gamma-\sin ^{2} \gamma\right) \sin 3 C\right]\right\}$

$\div\left[s_{11}+\left(s_{11}+s_{33}-s_{44}-2 s_{13}\right) \cos ^{4} \gamma-\left(2 s_{11}-s_{44}-2 s_{13}\right) \cos ^{2} \gamma-s_{14} \sin ^{3} \gamma \cos \gamma\right.$ $\cos 3 C]$

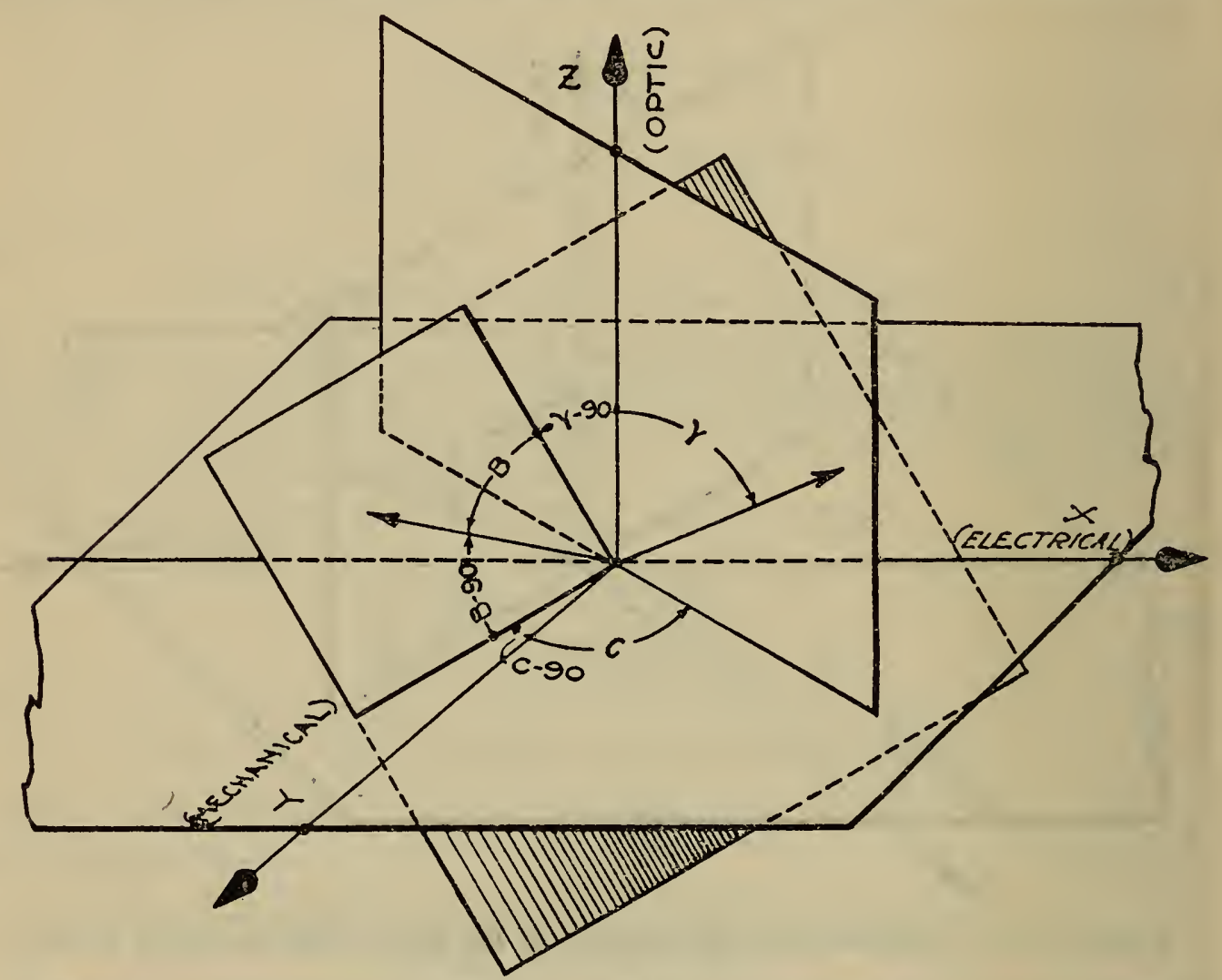

FIĞURE 20.-Diagrammatic illustration of the angles represented by $\gamma, C$, and $B$.

Voigt experimentally determined the following values of the six elastic constants for quartz

$$
\begin{aligned}
& s_{11}=12.734 \times 10^{-10}( \pm 0.001) \begin{array}{l}
\mathrm{cm}^{2} / \mathrm{g} \\
\mathrm{cm}^{2} / \mathrm{g}
\end{array} \\
& s_{33}=9.705 \times 10^{-10}( \pm 0.011) \begin{array}{l}
\mathrm{cm}^{2} / \mathrm{g} \\
\mathrm{cm}^{2} / \mathrm{g}
\end{array}
\end{aligned}
$$

Using the mean values, and the value $g=980.6$

$$
\begin{aligned}
& s_{11}=12.985 \times 10^{-13} \mathrm{~cm}^{2} / \text { dyne }-s_{12}=1.661 \times 10^{-13} \mathrm{~cm}^{2} / \text { dyne } \\
& s={ }_{33} 9.897 \times 10^{-13} \mathrm{~cm}^{2} / \text { dyne }-s_{13}=1.515 \times 10^{-13} \mathrm{~cm}^{2} / \text { dyne } \\
& s_{44}=20.054 \times 10^{-13} \mathrm{~cm}^{2} / \text { dyne }-s_{14}=4.314 \times 10^{-13} \mathrm{~cm}^{2} / \text { dyne }
\end{aligned}
$$


With these values, (12) becomes

$\frac{10^{15}}{E}=1298.5+585.8 \cos ^{4} \gamma-894.6 \cos ^{2} \gamma+862.8 \sin ^{3} \gamma \cos \gamma \cos 3 C$

giving $E$ in dynes $/ \mathrm{cm}^{2}$. Similarly, (15) becomes

$\frac{10^{15}}{\mu}=2005.4+585.8 \cos ^{2} B \sin 2 \gamma+923.8 \sin ^{2} B \sin ^{2} \gamma+431.4$

$\left[\cos ^{2} B \sin 4 \gamma \cos 3 C-2 \sin ^{2} B \sin 2 \gamma \cos 3 C-2 \sin 2 B \sin \gamma\right.$

$\left.\left(2 \cos ^{2} \gamma-\sin ^{2} \gamma\right) \sin 3 C\right]$

giving $\mu$ in dynes $/ \mathrm{cm}^{2}$.

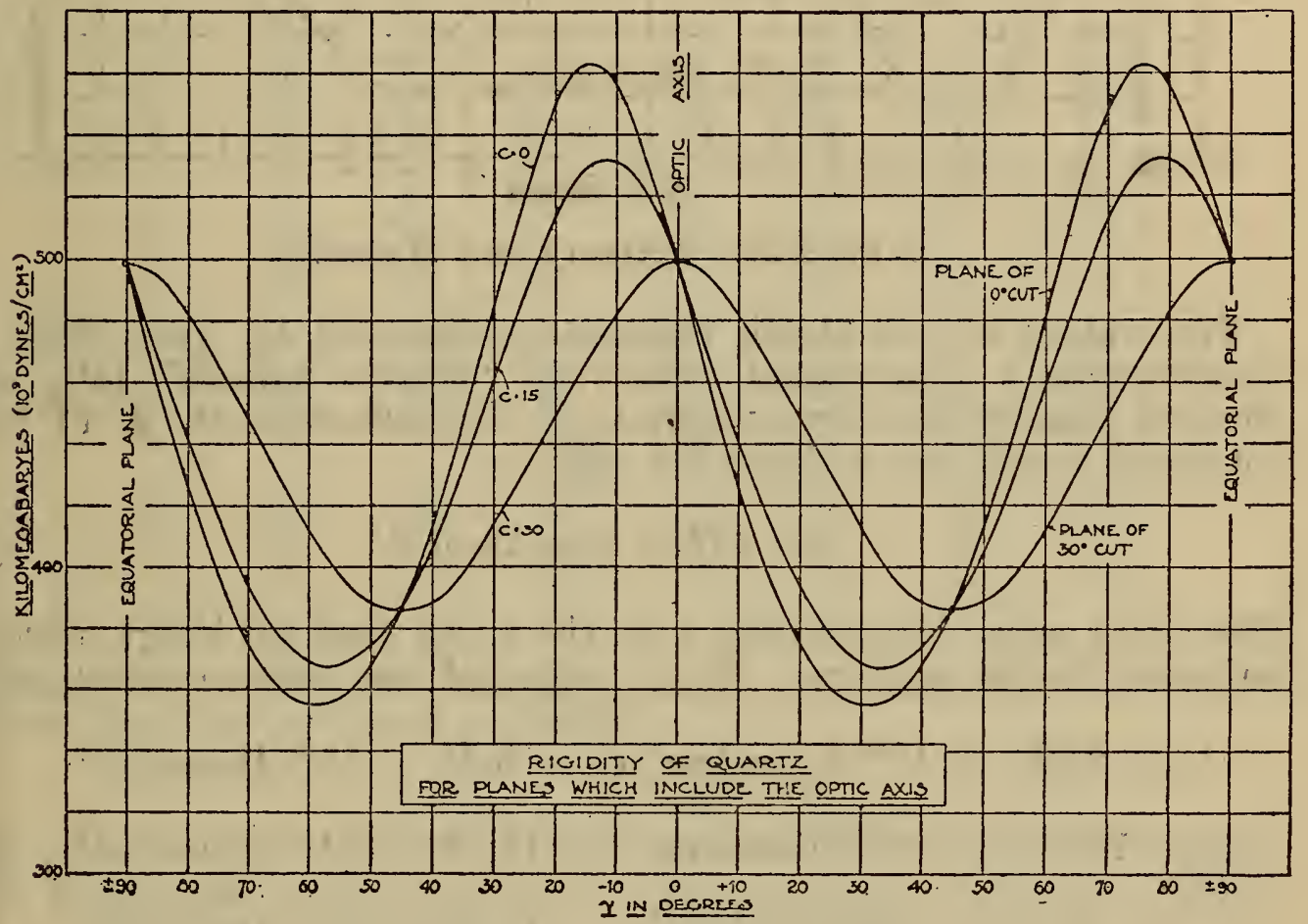

FIGURE 21.-Modulus of rigidity of quartz

This when simplified for planes containing the optic axis, becomes

$$
\frac{10^{15}}{\mu}=2005.4+585.8 \sin ^{2} 2 \gamma+431.4 \sin 4 \gamma \cos 3 C
$$
giving $\mu$ in dynes $/ \mathrm{cm}^{2}$

A graph of this is given in Figure 21. And the expression (17) for Poisson's ratio becomes

$$
\sigma=\left\{151.5-146.4 \cos ^{2} B \sin ^{2} 2 \gamma+14.6 \sin ^{2} B \sin ^{2} \gamma-1.078\right.
$$

$\left[\cos ^{2} B \sin 4 \gamma \cos 3 C-2 \sin ^{2} B \sin 2 \gamma \cos 3 C-2 \sin 2 B \sin \gamma\right.$

$\left.\left.\left(2 \cos ^{2} \gamma-\sin ^{2} \gamma\right) \sin 3 C\right]\right\}$

$\div\left[1298.5+585.8 \cos ^{4} \gamma-894.6 \cos ^{2} \gamma+862.8 \sin ^{3} \gamma \cos \gamma \cos 3 C\right]$ 
For planes including the optic axis, this reduces to

$$
\sigma=\frac{151.5-146.2 \sin ^{2} 2 \gamma-1.078 \sin 4 \gamma \cos 3 C}{1298.5-585.8 \cos ^{4} \gamma-894.6 \cos ^{2} \gamma+862.8 \sin ^{3} \gamma \cos \gamma \cos 3 C}
$$

a graph of which is given in Figure 22.

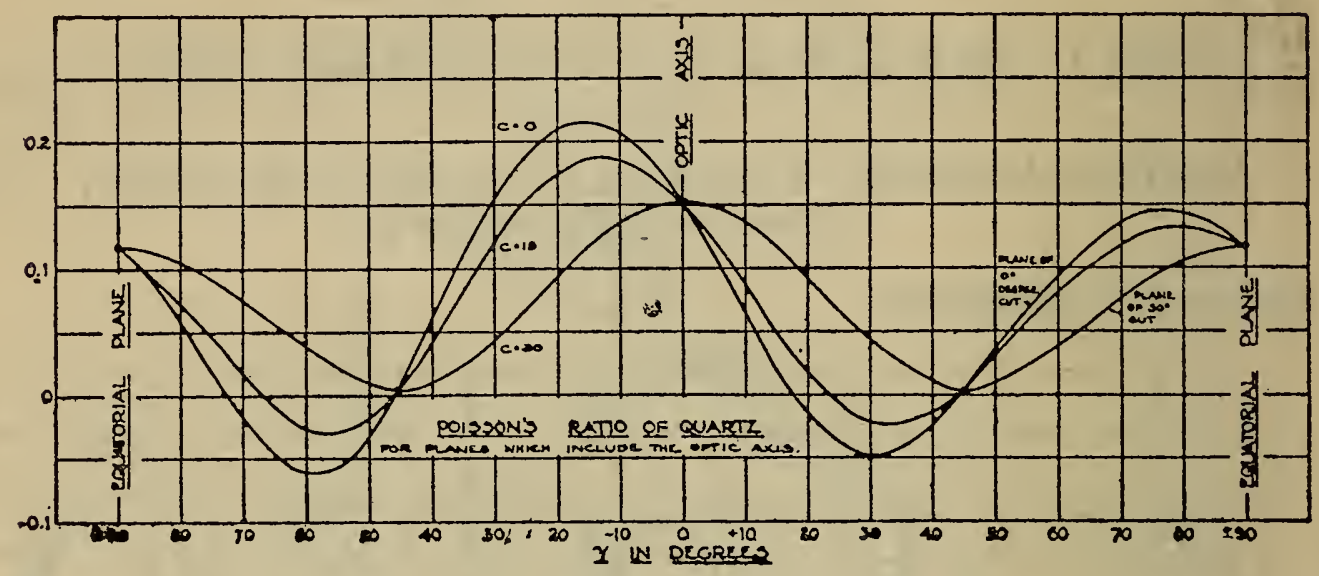

Frgure 22.-Poisson's ratio of quartz

The values of the elastic constants computed by Voigt from his experimentally determined values of "elastic moduli" $(20)$ were checked exactly by the authors, and the determinant, $\Delta$, of these constants was found to have the value

$$
\Delta=7.0727\left(\mathrm{~cm}^{2} / \text { dyne }\right)^{6}
$$

This must agree very closely with the value used by Voigt, which is unknown to the authors. These values of the elastic constants are:

$$
\begin{aligned}
& c_{11}=85.14 \times 10^{10} \mathrm{dynes} / \mathrm{cm}^{2} \quad c_{12}=6.95 \times 10^{10} \mathrm{dynes} / \mathrm{cm}^{2} \\
& c_{33}=105.36 \times 10^{10} \mathrm{dynes} / \mathrm{cm}^{2} \quad c_{13}=14.10 \times 10^{10} \mathrm{dynes} / \mathrm{cm}^{2} \\
& c_{44}=57.10 \times 10^{10} \mathrm{dynes} / \mathrm{cm}^{2} \quad c_{14}=16.82 \times 10^{10} \mathrm{dynes} / \mathrm{cm}^{2}
\end{aligned}
$$

It might be well to point out that within the limits of error, as specified by Voigt, of measurement of the elastic constants, Poisson's ratio is always greater than zero for the $30^{\circ}$ plane. However, interestingly enough, if values of these constants are chosen with the end in view of reducing as much as possible within these limits the minimum value of the ratio for this plane, the smallest value thus obtainable is found to be about half as large as the minimum obtained by using the mean value of these elastic constants. In other words, if the limits of error happened to be slightly wider, the minimum could then be caused, through proper choice of values of the constants, to become zero at $\gamma=\$ 45^{\circ}$, which, because of the form of the equation, would then cause the curve for the $0^{\circ}$ plane to pass through zero at this same angle. If it could be demonstrated that this ratio should be zero at $\gamma= \pm 45^{\circ}$ for any or all planes that include the optic axis, the number of independent elastic constants would thereby be reduced to five. 
VII. Appendix II,-THE EVALUATION OF YOUNG'S MODULUS

Using the equation ${ }^{32} \frac{10^{15}}{E}=1298+587 \cos ^{4} \gamma-895 \cos ^{2} \gamma+862 \sin ^{3} \gamma-$ cos $\gamma \cos 3 C$ expressing $E$ in dynes $/ \mathrm{cm}^{2}{ }_{1}$ values of Young's modulus were computed for planes passing through the optic axis at various angles, $C$, from the $\mathrm{YZ}$ plane, and for various angles, $\gamma$, measured from the optic axis, in these planes. (See again fig. 19.) These values are to be found tabulated in Table 2, and prepared in the form of a graph in Figure 23. In Figure 24 is reprinted ${ }^{33}$ a photograph showing a surface constructed to represent the locus of Young's modulus as a radius vector.

TABLE 2

\begin{tabular}{|c|c|c|c|c|c|c|c|}
\hline$\gamma_{8}$ & $C=0^{\circ}$ & $C=5^{\circ}$ & $C=10^{\circ}$ & $C=15^{\circ}$ & $C=20^{\circ}$ & $C=25^{\circ}$ & $C=30^{\circ}$ \\
\hline $\begin{array}{l}-90^{\circ} \\
-80^{\circ} \\
-70^{\circ} \\
-60^{\circ} \\
-50^{\circ}\end{array}$ & $\begin{array}{r}770 \\
886 \\
1,045 \\
1,203 \\
1,283\end{array}$ & $\begin{array}{r}770 \\
882 \\
1,036 \\
1,189 \\
1,269\end{array}$ & $\begin{array}{r}770 \\
871 \\
1,011 \\
1,151 \\
1,230\end{array}$ & $\begin{array}{r}770 \\
855 \\
972 \\
1,095 \\
1,173\end{array}$ & $\begin{array}{r}770 \\
833 \\
927 \\
1,030 \\
1,106\end{array}$ & $\begin{array}{r}770 \\
810 \\
879 \\
963 \\
1,037\end{array}$ & $\begin{array}{l}770 \\
786 \\
833 \\
900 \\
972\end{array}$ \\
\hline $\begin{array}{r}-40^{\circ} \\
-30^{\circ} \\
-20^{\circ} \\
-10^{\circ} \\
0^{\circ}\end{array}$ & $\begin{array}{l}1,251 \\
1,158 \\
1,072 \\
1,023 \\
1,010\end{array}$ & $\begin{array}{l}1,241 \\
1,154 \\
1,071 \\
1,023 \\
1,010\end{array}$ & $\begin{array}{l}1,215 \\
1,141 \\
1,067 \\
1,022 \\
1,010\end{array}$ & $\begin{array}{l}1,175 \\
1,122 \\
1,061 \\
1,021 \\
1,010\end{array}$ & $\begin{array}{l}1,127 \\
1,099 \\
1,053 \\
1,020 \\
1,010\end{array}$ & $\begin{array}{l}1,076 \\
1,072 \\
1,045 \\
1,019 \\
1,010\end{array}$ & $\begin{array}{l}1,026 \\
1,045 \\
1,036 \\
1,018 \\
1,010\end{array}$ \\
\hline $\begin{array}{l}10^{\circ} \\
20^{\circ} \\
30^{\circ} \\
40^{\circ} \\
50^{\circ}\end{array}$ & $\begin{array}{r}1,014 \\
1,002 \\
952 \\
869 \\
783\end{array}$ & $\begin{array}{r}1,014 \\
1,003 \\
955 \\
874 \\
789\end{array}$ & $\begin{array}{r}1,014 \\
1,006 \\
963 \\
888 \\
804\end{array}$ & $\begin{array}{r}1,015 \\
1,012 \\
977 \\
910 \\
830\end{array}$ & $\begin{array}{r}1,016 \\
1,019 \\
996 \\
942 \\
868\end{array}$ & $\begin{array}{r}1,017 \\
1,027 \\
1,019 \\
980 \\
916\end{array}$ & $\begin{array}{r}1,018 \\
1,036 \\
1,045 \\
1,026 \\
972\end{array}$ \\
\hline $\begin{array}{l}00^{\circ} \\
70^{\circ} \\
80^{\circ} \\
90^{\circ}\end{array}$ & $\begin{array}{l}719 \\
692 \\
707 \\
770\end{array}$ & $\begin{array}{l}724 \\
696 \\
710 \\
770\end{array}$ & $\begin{array}{l}739 \\
708 \\
717 \\
770\end{array}$ & $\begin{array}{l}764 \\
728 \\
728 \\
770\end{array}$ & $\begin{array}{l}799 \\
755 \\
745 \\
770\end{array}$ & $\begin{array}{l}845 \\
790 \\
764 \\
770\end{array}$ & $\begin{array}{l}900 \\
833 \\
786 \\
770\end{array}$ \\
\hline
\end{tabular}

The maxima and minima of these curves of Young's modulus as an angular function are found to fall at

$$
\gamma=-48^{\circ} 15^{\prime} \quad \gamma=0^{\circ} \quad \gamma=+10^{\circ} 50^{\prime} \quad \gamma=+71^{\circ} 35^{\prime}
$$

for $C=0^{\circ}$, in which directions the modulus takes the respective values

$$
E=1285 \times 10^{9} \quad E=1010 \times 10^{9} \quad E=1014 \times 10^{9} \quad E=691 \times 10^{9}
$$

the units being dynes $/ \mathrm{cm}^{2}$.

The maxima and minima for $C=30^{\circ}$ are to be found at

$$
\gamma= \pm 90^{\circ} \quad \gamma= \pm 29^{\circ} 6^{\prime} \quad \gamma=0^{\circ}
$$

where the corresponding values of Young's modulus are, respectively,

$$
E=770 \times 10^{9} \quad E=1045 \times 10^{9} \quad E=1010 \times 10^{9}
$$

in dynes $/ \mathrm{cm}^{2}$.

In Figure 25 is shown the sense in which the angle $\gamma$ is to be taken with respect to the polarization and sense of optical rotation of a crystal. The figure shows that the sense of optical rotation of a given piece of quartz may be determined by the orientation of its elastic properties with respect to the sense of its piezo-electric polarization.

"Based on $g=981$ dynes, and Voigt's experimentally determined "moduli." This equation agrees with

that given by Sosman, Properties of Silica, ature. The one reprinted here represents conditions at $15^{\circ} \mathrm{C}$. The four were originally presented by A. Perrier and R. de Maudrot, Elasticité et Symétrie du Quartz aux Températures Élevées, Mémoires de la Société Vaudoise des Sciences Naturales, 1; pp. 333-363; 1923. 


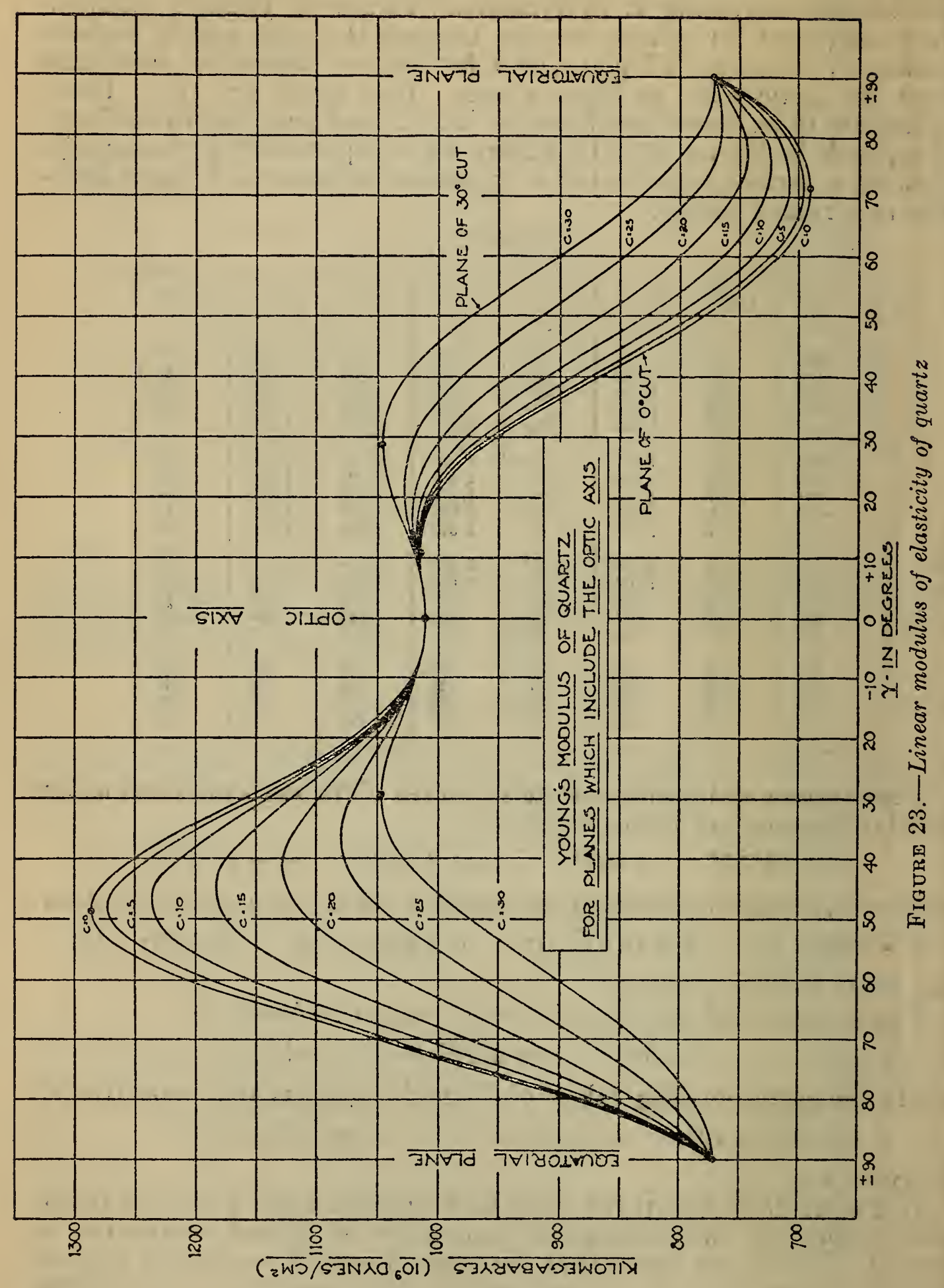




\section{B. S. Journal of Research, RP356}

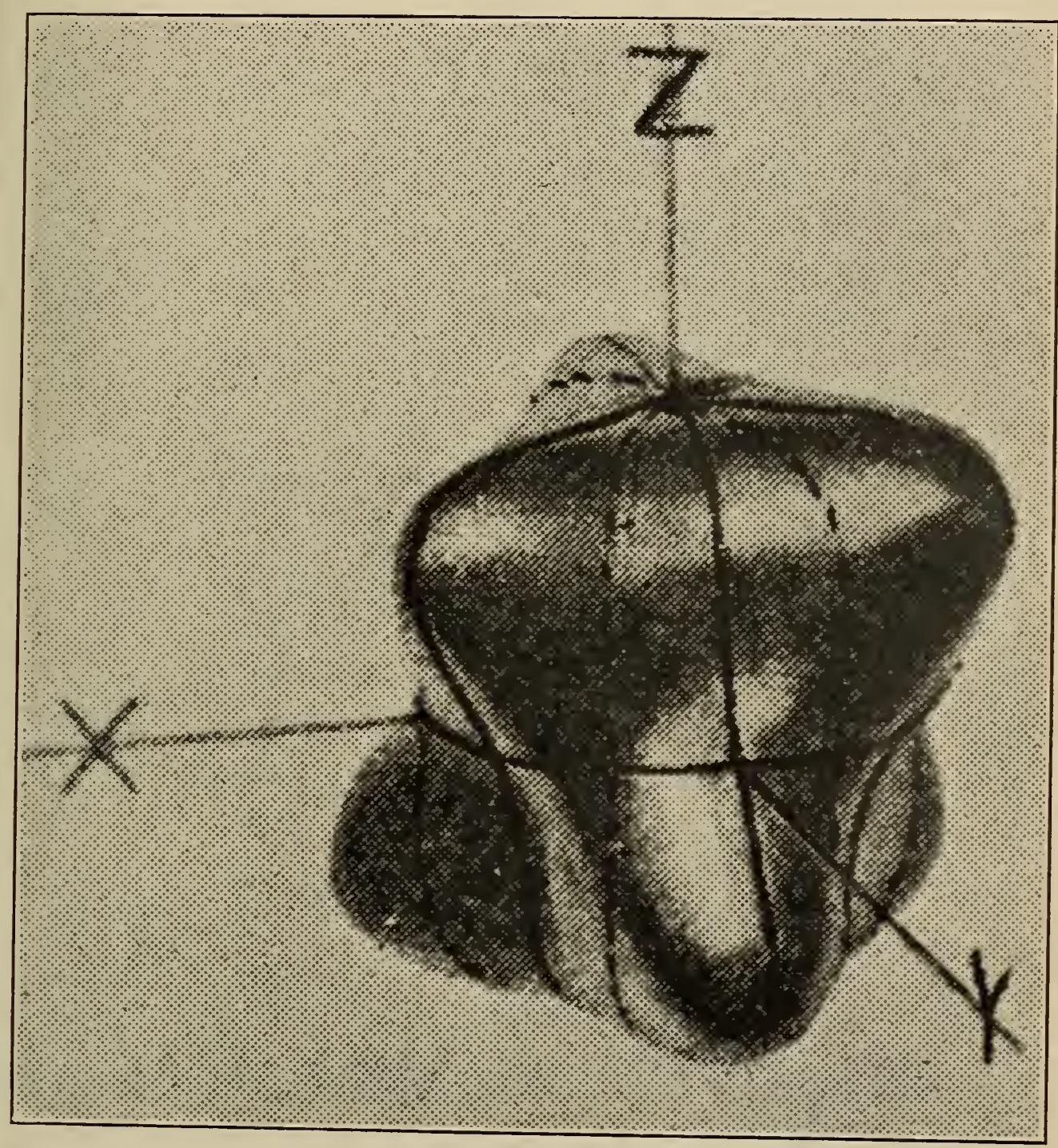

FIGURE 24.- Surface representing the locus of Young's modulu's as a radius
vector (See Note 33.) 
Or, with knowledge of any two or these three characteristics, the other is determined. ${ }^{34}$

It has been found that a very convenient means of determining the sense of the piezo-electric polarization lies in the application of stresses. As may be easily seen, a very large rate of change of stress may be obtained by the sudden releasing of the crystalline plate from forces exerted through a device of high mechanical leverage. And the vacuum tube circuit lends itself quite readily to the measure-

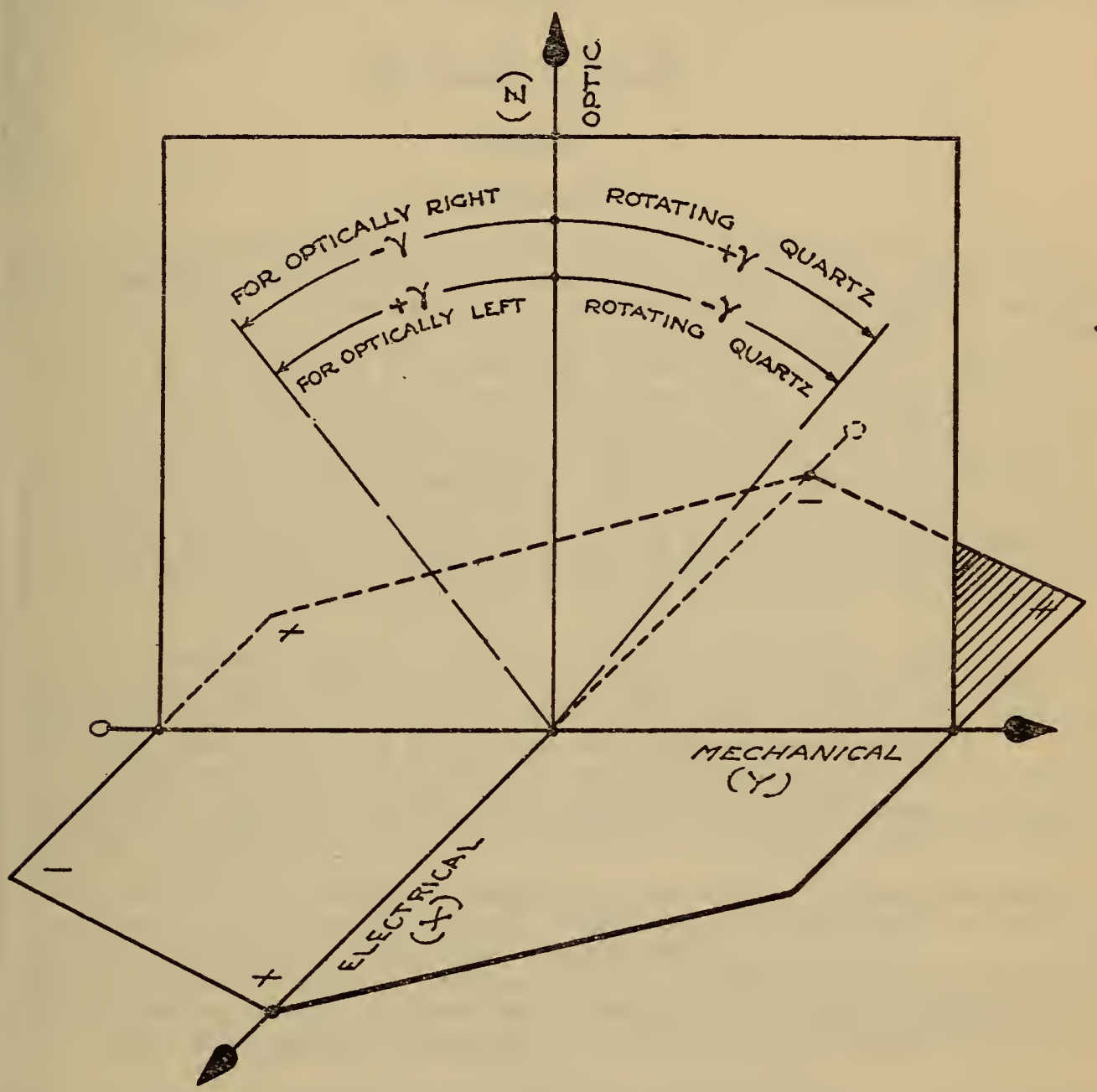

FIGURE 25.-Diagrammatic representation of orientation of the angle $\gamma$ with respect to sense of optical rotation (facing source) and piezo-electric polarization

ment of the time rate of change of the accompanying polarization. Thus, for the case in which the time derivative of the polarization is measured, the polarity accompanying a decrease of pressure applied parallel to an electric axis is to be identified with a corresponding opposing polarity shown in Figure 25 for the orientation of the elastic properties shown therein.

Washington, June 18, 1931.

${ }^{34}$ This is in accord with observations of A. Meissner to be found in the publication by him, Uber PiezoElektrische Kristalle bei Hochfrequenz. Zs. f. techn. Phys., 8, pp. 74-77; 1927. 